\title{
Parameter setting of meta-heuristic algorithms: a new hybrid method based on DEA and RSM
}

\author{
Elham Shadkam ${ }^{1}$ (D)
}

Received: 2 September 2021 / Accepted: 31 October 2021 / Published online: 17 November 2021

(c) The Author(s), under exclusive licence to Springer-Verlag GmbH Germany, part of Springer Nature 2021

\begin{abstract}
The parameter setting of meta-heuristic algorithms is one of the most effective issues in the performance of meta-heuristic algorithms and is usually done experimentally which is very time-consuming. In this research, a new hybrid method for selecting the optimal parameters of meta-heuristic algorithms is presented. The proposed method is a combination of data envelopment analysis method and response surface methodology, called DSM. In addition to optimizing parameters, it also simultaneously maximizes efficiency. In this research, the hybrid DSM method has been used to set the parameters of the cuckoo optimization algorithm to optimize the standard and experimental functions of Ackley and Rastrigin. In addition to standard functions, in order to evaluate the performance of the proposed method in real problems, the parameter of reverse logistics problem for COVID-19 waste management has been adjusted using the DSM method, and the results show better performance of the DSM method in terms of solution time, number of iterations, efficiency, and accuracy of the objective function compared to other.
\end{abstract}

Keywords Meta-heuristic algorithms · Parameter setting $\cdot$ Cuckoo algorithm · Response surface methodology $\cdot$ Data envelopment analysis $\cdot$ Waste management $\cdot$ COVID-19

\section{Introduction and literature review}

Many real-world problems can be modeled by operation research techniques and then optimized in a variety of ways. The goal of optimization is to find the best acceptable solution, given the constraints and assumptions of the problem. In each optimization problem, there are decision variables that are limited by a set of constraints or conditions. If the decision variables are discrete in nature, such problems are called combinatorial optimization problems. Because many potential solutions must be considered to solve combinatorial optimization problems, these problems are known as NP-hard problems. In many real-world problems, the solution time is increased non-linearly using exact optimization methods. To solve this problem, regardless of the accuracy of the solution, it is possible to create an acceptable solution

Responsible Editor: Philippe Garrigues

Elham Shadkam

e.shadkam@khayyam.ac.ir

1 Department of Industrial Engineering, Faculty of Engineering, Khayyam University, Mashhad, Iran in a much shorter and more logical time by using approximate optimization methods. Therefore, optimization methods and algorithms are divided into two categories: exact and approximate methods. Exact methods are able to find the optimal solution accurately but are not efficient enough in NP-hard optimization problems. Thus, heuristic algorithms were first developed, which are a set of approximate algorithms, but these algorithms are generally designed for a specific problem and often cannot be used for other problems. Therefore, meta-heuristic algorithms were proposed that are independent of a specific problem. The performance of these algorithms is highly dependent on their parameters. In order for these algorithms to work optimally, it is necessary to find specific values for each parameter. Therefore, the problem of parameter setting of meta-heuristic algorithms has been raised. Adjusting the parameters of meta-heuristic algorithms is an effective factor in the performance of these algorithms, so this problem has been considered in many previous studies and various methods have been proposed for it (Lobo et al., 2007; Yazdani, et al., 2017a, 2017b). The importance of the parameters of any optimization algorithm, especially meta-heuristic algorithms, is inevitable (Yazdani et al., 2016). The optimal values of these parameters, which 
generally depend on the characteristics of the parameter and the problem, have a significant impact on the performance of these algorithms and better search of the solution space (Najafi \& Behnoud, 2015; Yazdani, et al., 2017a, 2017b). One of the recently introduced meta-heuristic algorithms is the cuckoo optimization algorithm (COA). The use of the COA has many applications in various engineering sciences. This algorithm, like other meta-heuristic algorithms, is sensitive to parameter setting. In using the COA, precise adjustments must be made in the execution of the algorithm, determination of the appropriate combination of parameters, final execution of the algorithm, and validation of the solutions. Previous research has used methods such as trial and error, experimental design, and Taguchi method to adjust the parameters of this algorithm (Azadeh et al., 2013). The problem of setting the parameters of meta-heuristic algorithms is so important and noteworthy that an article entitled Why Tuning the Control Parameters of Meta-heuristic Algorithms Is So Important for Fair Comparison? has been proposed in this regard (Kazikova et al., 2020). In a study, Cheng and Chang (2007) proposed a genetic algorithm to optimize the scheduling problem and proposed a hybrid method for optimizing the genetic algorithm parameters using the design of Taguchi experiments. They tested and optimized seven algorithm parameters including initial solutions, selection method, intersection approach, mutation rate, initial population size, algorithm velocity, and mutation method. Naderi et al. (2009) used the Taguchi method to adjust the parameters of the simulated annealing (SA) algorithm. They considered parameters such as initial solutions, coding pattern, and local search structure as controllable factors of SA and different levels for each factor. They then considered and optimized these factors using the Taguchi method. In a study, Bartz-Beielstein and Markon (2004) proposed a method for parameters setting of complex real-world optimization problems. This method is a combination of statistical design of experiment methods, regression analysis, design and analysis of computer experiments, and regression tree that has been used to set the parameters of the SA and evolutionary algorithm. In a paper, Ridge and Kudenko (2007) set the parameter of the ant colony optimization algorithm by designing experiments to solve the traveling salesman problem, which used the response surface methodology to evaluate the quality and time of the solutions. In their research, Fallahi et al. (2014) examined the parameters of the ant colony algorithm for traveling salesman problem, which were performed in five stages: parameter profile screening, clustering, parameter screening, response procedure methodology, and finally optimization. In a paper, solving the problem of vehicle routing using the Memetic algorithm, Saremi et al. (2007) considered setting the desired parameters using experimental design method and analysis of variance to investigate the interactions. Xu et al. (1998) examined the parameter setting in the Tabu search algorithm using statistical tests and experimental design. In this study, the decision tree minimization problem is considered by explaining three types of neighbor structure selection methods. This method has been used by other researchers to adjust the parameters of the Tabu search algorithm to solve the problem of vehicle routing. Beielstein et al. (2002) examined the parameters of the particle swarm optimization algorithm using experimental design techniques and analyzed their important parameters and interactions. In an article, Ridge (2007) adjusts the parameters of one type of the ant colony algorithms to solve the traveling salesman problem, and the results show the better performance of the mentioned algorithm with standardized parameters. In a research, Šilc et al. (2015) proposed a data mining approach to set the performance of meta-heuristic algorithms. In this paper, the idea of learning, a model for algorithm behavior using data mining is presented as the results obtained in parameter setting. A paper presented by Veček et al. (2016) includes a method called the chess ranking system. This approach has been used to compare and score evolutionary algorithms. In that method, the desirability and performance of a combination of parameters are obtained by comparing with other structures based on their score, deviation from the score, and the distance of the score. During the performance and in each iteration, the bad structures are significantly eliminated and new structures are obtained through mutations and combinations of existing structures. The results of this method show that there is not always a significant difference in the assumption of zero statistical tests, but the method mentioned in the paper shows better performance when using similar parametric structures. Also, parameter setting with this method has been faster than other methods such as the competitive method, and there is no limit in setting absolute parameters. The researches done in this field are very diverse and extensive (Table 1), and the studies done in this field are reviewed.

One of the methods used for parameter setting of metaheuristic algorithms is response level methodology (RSM). RSM is a combination of mathematical and statistical techniques that is widely used for modeling and data analysis. In this method, response variables (outputs) are influenced by several independent variables (inputs), and the goal is to obtain the best values of inputs in order to optimize outputs (Hinkelmann \& Kempthorne, 1994). One of the first researches to determine the parameters of meta-heuristic algorithms using RSM is Wang and Wu's (1999) research, in which a six-step RSM-based process for identifying and optimizing the SA algorithm with computational time constraints has been performed. In a paper, Najafi and Behnoud (2015) presented a combined algorithm of RSM and data envelopment analysis (DEA) to adjust the parameters of meta-heuristic algorithms. Using the RSM, they set the parameters of a genetic algorithm to optimize the machine 
Table 1 Review of the papers on parameter setting of meta-heuristic algorithms

\begin{tabular}{|c|c|c|c|}
\hline No & Authors (year) & Meta-heuristic algorithm & Methods applied \\
\hline 1 & Xu et al. (1998) & Tabu search algorithm & Statistical tests and experiments design \\
\hline 2 & Beielstein et al. (2002) & Particle swarm optimization algorithm & Experiment design \\
\hline 3 & Bartz-Beielstein and Markon (2004) & Simulated annealing algorithm & $\begin{array}{l}\text { Experimental design, regression analysis, design } \\
\text { and analysis of computer experiments, and } \\
\text { regression tree }\end{array}$ \\
\hline 4 & Ridge (2007) & Ant colony optimization algorithm & $\begin{array}{l}\text { Design of experiments and response surface } \\
\text { methodology }\end{array}$ \\
\hline 6 & Joshi and Bansal (2020) & Ant colony optimization algorithm & $\begin{array}{l}\text { Parameter specification screening, clustering, } \\
\text { parameter screening, RSM, and optimization }\end{array}$ \\
\hline 7 & Saremi et al. (2007) & Memetic algorithm & Design of experiments and variance analysis \\
\hline 8 & Šilc et al. (2015) & Meta-heuristic algorithm & Data mining \\
\hline 9 & Veček et al. (2016) & Evolutionary algorithms & Comparison and scoring \\
\hline 10 & Najafi and Behnoud (2015) & Genetic algorithm & RSM and DEA \\
\hline 11 & Saeheaw (2020) & HCSCROCFO-3Opt algorithm & A random manner \\
\hline 12 & Odili and Fatokun (2020) & African buffalo optimization algorithm & Mathematical modeling \\
\hline 13 & Gomes and de Almeida (2020) & Sunflower optimization & Statistical method of mixture design \\
\hline 14 & Joshi and Bansal (2020) & Gravitational search algorithm & $\begin{array}{l}\text { Topological characteristics of the given optimi- } \\
\text { zation problem }\end{array}$ \\
\hline 15 & Do Ngoc Luu and Anh (2021) & Deep belief networks to predict time series data & Harmony search algorithm \\
\hline 16 & Özakın and Kaya (2020) & Air-based PVT system & Taguchi method and ANOVA \\
\hline 17 & Walker and Craven (2020) & $\begin{array}{l}\text { Evolutionary multi- and many-objective opti- } \\
\text { mization }\end{array}$ & A visualization approach \\
\hline 18 & Phan et al. (2020) & $\begin{array}{l}\text { Evolutionary algorithms and swarm intelligence } \\
\text { algorithms }\end{array}$ & Dynamic parameter setting techniques \\
\hline 19 & Thirumalai et al. (2021) & Non-dominated sorting genetic algorithm & $\begin{array}{l}\text { Technique for order preference by similarity to } \\
\text { ideal solution }\end{array}$ \\
\hline 20 & Črepinšek et al. (2019) & Multi-objective evolutionary algorithms & A novel MOCRS-tuning method \\
\hline 21 & Cheng et al. (2021) & $\begin{array}{l}\text { Genetic algorithm and particle swarm optimiza- } \\
\text { tion }\end{array}$ & $\begin{array}{l}\text { Auto-tuning symbiotic organisms search algo- } \\
\text { rithm }\end{array}$ \\
\hline 22 & Alavi et al. (2021) & $\begin{array}{l}\text { A variable neighborhood search meta-heuristic } \\
\text { method }\end{array}$ & Conventional sequential optimization method \\
\hline 23 & Devarapalli and Bhattacharyya (2021) & Power system stabilizer & Sine-cosine algorithm \\
\hline 24 & Mergos and Yang (2021) & Flower pollination algorithm & $\begin{array}{l}\text { A simple non-iterative, single-stage sampling } \\
\text { tuning method }\end{array}$ \\
\hline 25 & Tien Bui et al. (2021) & Neural computing & Whale optimization algorithm \\
\hline
\end{tabular}

scheduling problem assuming sequence-dependent preparation times. In their method, in order to optimize the parameters of the algorithm, only the optimization of the objective function has been considered and the solution time of the algorithm has not been addressed. The use of the DEA method in optimization problems is very common and can be referred to Shadkam (2021a, 2021b, 2021c) that in a twophase algorithm using DEA to optimize the objective function and maximize the efficiency of the problem simultaneously. Also, Shadkam and Bijari (2015) in a research have used the combination of RSM and DEA in order to optimize multi-objective problems for bank branches. For the first time in a review paper, Phan et al. (2020) have reviewed and classified the various methods of parameter setting of evolutionary algorithms. These methods are divided into two groups: parameter tuning and parameter control methods. Parameter tuning techniques are used to select offline parameters before the optimization algorithm is executed, but online parameter control techniques are used in dynamic optimization problems during an algorithm execution or after each algorithm execution. According to this classification, one of the most widely used and popular methods in the field is the experimental design of experiments method (DOE). In this method, the parameters are adjusted to create the best solution for the objective function. The Taguchi method is mostly used in this field. In fact, because only one solution can be examined, the value of the objective function is usually considered, and if we want to consider other response such as the number of iterations and the execution time of the algorithm, this process must be repeated 
separately for each response. Finally, the parameters created will not perform well at all responses because each response is optimized separately.

In our study, by combining DEA and RSM methods, a hybrid method called DSM is presented. The name of the proposed hybrid method is taken from the methods used in it. This method has various applications that will be discussed in future research by the authors of this paper. In principle, this method is presented to optimize multi-objective problems and another application is to parameterize the meta-heuristic algorithm, which has been used in this paper to optimize the parameters of the COA. The COA is one of the newest and most powerful meta-heuristic algorithms that has the ability to solve discrete and continuous problems. The parameter setting process of this algorithm is performed by the proposed DSM method, with the help of data obtained from the design of experiments and the implementation of the algorithm for both standard and real-time functions. In the hybrid DSM method, first, a number of decision-making units (DMUs) are selected, and the values of their inputs and outputs are determined. Then, the efficiency values of the DMUs are calculated using the DEA method. Then, with the RSM method, the response surfaces are made, which includes an efficiency surface and the response surfaces to the number of output variables. The efficiency surface is optimized, and the values of the optimal independent variables are obtained, then according to the optimal independent variables, the optimal response variables are obtained. The obtained independent variables and the optimal response variables are considered as a suitable configuration for the COA. Similarly, two tools, DEA and RSM, have been used for optimizing multi-surface problems in power plants of IRAN (Shadkam, 2021a, 2021b, 2021c). The proposed method of the paper overcome the shortcoming of DOE method and Najafi and Behnoud (2015) algorithm. In this method, in order to set the parameters, in addition to the value of the objective function, other responses (execution time and number of iterations) are also examined. Also, all three responses are optimized simultaneously, which ultimately leads to a better configuration for the algorithm.

In order to implement the proposed method in the real world, the medical waste management problem is examined. Medical wastes are one of the most important hazardous wastes and carry a large number of pathogenic bacteria (Sangkham, 2020). This issue has special importance and place in research, and many articles on the design of medical wastes logistics networks have been presented (Kargar et al., 2020b). The problem of waste disposal in hospitals is a very important problem that has been the subject of much research, including Wang et al. (2020), Fletcher et al. (2021), Adu et al. (2020), and Homayouni and Pishvaee (2020). Due to the global outbreak of the coronavirus, the volume of medical wastes and the dangers posed by it have increased dramatically (Ozkaya et al., 2020). In this regard, Shadkam (2021a, 2021b, 2021c) has presented a mixed integer model for the management of COVID-19 wastes, especially its vaccine. The purpose of this model is to design a reverse supply chain model for safe and optimal disposal of medical wastes (focusing on corona vaccine wastes). Due to the containers and equipment used in COVID-19 vaccine packaging for easy transportation and maintenance, this model can be a great help in returning these containers to the factory and recycling them, saving you money and time. Therefore, the proposed model directs non-recyclable wastes to disposal and returns recyclable wastes such as COVID-19 vaccine containers to the plant after disinfection. Many researches have been done in the field of medical waste management, an example of which can be seen in Table 2 .

In this paper, the parameter setting of inverse logistics problem of corona waste management has been investigated. Today, reverse logistics is one of the main activities of supply chain management that covers all physical activities related to returned products (such as collection, recovery, recycling, and destruction) (Julianelli et al., 2020). In this regard, proper design and implementation of reverse logistics, in addition to increasing customer satisfaction, reduce inventory and shipping costs. In this paper, the parameter setting of a mixed integer linear programming model for the design of an integrated direct and reverse logistics network is investigated. Due to the prevalence of coronavirus (COVID-19) and the increase in medical waste, the need for a reverse logistics system for waste management is strongly felt. For this purpose, the inverse logistics model in the field of coronavirus waste management, especially vaccine waste, has been investigated. This model was introduced by Shadkam (2021a, 2021b, 2021c). This model is solved using the cuckoo optimization algorithm, and before solving using the proposed DSM method, the cuckoo algorithm parameter will be adjusted for the inverse logistics problem. In the following research, in the next section, the COA is described, then the proposed DSM method is presented, and how to implement it to set the parameters of meta-heuristic algorithms will be examined. In the next section, the parameters of the COA are adjusted with the help of the Ackley and Rastrigin functions. The verification of the proposed method is examined through four approaches, and the results will be reviewed and interpreted. These approaches include the Taguchi method, RSM, and Najafi and Behnoud (2015) method. In the next section, the cuckoo algorithm parameter is adjusted to solve the inverse logistics problem of COVID-19 waste and is compared with the experimental approach of parameter setting. 
Table 2 Recent research in medical waste (Shadkam, 2021a, 2021b, 2021c)

\begin{tabular}{|c|c|c|c|c|c|c|c|c|}
\hline No & Authors & Multi-objective & Multi-period & Multi-product & Uncertainty & Case study & Approach & Software \\
\hline 1 & $\begin{array}{l}\text { Shih and Lin } \\
\text { (2003) }\end{array}$ & $*$ & $*$ & & & China & $\begin{array}{c}\text { MILP Dynamic } \\
\text { programming }\end{array}$ & Lingo GIS \\
\hline 2 & $\begin{array}{l}\text { Kargar, et al. } \\
(2020 a, 2021 b)\end{array}$ & $*$ & $*$ & $*$ & $*$ & Iran & $\begin{array}{l}\text { MILP Fuzzy goal } \\
\text { programming } \\
\text { Robust possibility } \\
\text { Programming }\end{array}$ & Lingo \\
\hline 3 & Osaba et al. (2019) & & $*$ & $*$ & & Spain & $\begin{array}{l}\text { MILP Bat algo- } \\
\text { rithm Firefly } \\
\text { algorithm }\end{array}$ & Matlab \\
\hline 4 & Gergin et al. (2019) & $*$ & $*$ & $*$ & & Turkey & $\begin{array}{l}\text { MILP Artificial bee } \\
\text { colony }\end{array}$ & Microsoft Visual C\# \\
\hline 5 & Vickers (2017) & & $*$ & & & Greece & $\begin{array}{l}\text { MILP Genetic } \\
\text { algorithm Monte } \\
\text { Carlo simulation }\end{array}$ & Evolver Crystal Ball \\
\hline 6 & $\begin{array}{c}\text { Alshraideh and } \\
\text { Qdais (2017) }\end{array}$ & $*$ & $*$ & & $*$ & Jordan & $\begin{array}{l}\text { MILP Genetic } \\
\text { algorithm }\end{array}$ & Matlab \\
\hline 7 & $\begin{array}{l}\text { Budak and } \\
\text { Ustundag (2017) }\end{array}$ & & $*$ & & & Turkey & MILP & Fico Xpress IVE \\
\hline 8 & Nolz et al. (2014) & $*$ & $*$ & $*$ & & France & MILP & $\begin{array}{l}\text { Adaptive large } \\
\text { neighborhood } \\
\text { search }\end{array}$ \\
\hline 9 & Almeida (2010) & & & & $*$ & Portugal & MILP & GAMS \\
\hline 10 & Shi et al. (2009) & & $*$ & & & China & $\begin{array}{l}\text { MILP Genetic } \\
\text { algorithm }\end{array}$ & Matlab \\
\hline 11 & $\begin{array}{c}\text { Shadkam (2021a, } \\
\text { 2021b, 2021c) }\end{array}$ & & & & & Coronavirus & MILP COA & Matlab Lingo \\
\hline
\end{tabular}

\section{Introduction of the COA}

This algorithm was proposed by Rajabioun (2011) and is inspired by the life of a cuckoo bird. In various papers, the performance of this algorithm has been compared with other similar algorithms, which can be referred to (Kahramanli, 2012) and (Shadkam \& Bijari, 2014) for more information in this regard. This algorithm has been used in various fields, such as production planning (Akbarzadeh \& Shadkam, 2015), portfolio selection (Shadkam et al., 2015), supplier selection (Shadkam \& Bijari, 2017), and solving multi-objective optimization problems (Gorjestani et al., 2015; Shadkam \& Jahani, 2015; and Borhanifar \& Shadkam, 2016), supply chain problem (Shadkam et al., 2021), and resource leveling in control project management (Shadkam, 2021a, 2021b, 2021c). Due to the good performance of this algorithm, improved versions of this algorithm have also been presented (Shadkam \& Bijari, 2020). The flowchart of this algorithm is presented in Fig. 1. In the COA algorithm, similar to other evolutionary algorithms, it starts with a random population of initial cuckoos. Each cuckoo has positions called a habitat (relation 1), which indicates the array of the problem-solving variables.
Habitat $=\left[x_{1}, x_{2}, \ldots, x_{\text {Nvar }}\right]$

Each cuckoo lays a number of eggs according to its assigned egg-laying radius (relation 2). Some of these eggs are destroyed, and some of the eggs remain and become adult cuckoos. Adult cuckoos look for places where they have a better chance of survival or where the average value of the objective function is optimal in those areas. After identifying the optimal location, each cuckoo migrates with some deviation from the optimal location and starts laying eggs. Due to dietary restrictions, only a few cuckoos can survive. Therefore, cuckoos with inappropriate values of the objective function are removed, and only the more efficient cuckoos will be transferred to the next iteration of the algorithm. This process is repeated in the same order as mentioned to establish the stop condition.

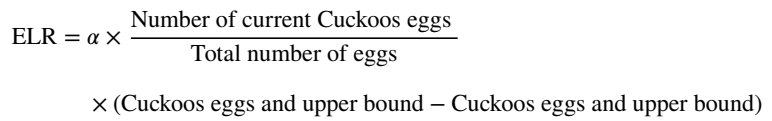


Fig. 1 The flowchart of the COA (Rajabioun, 2011)

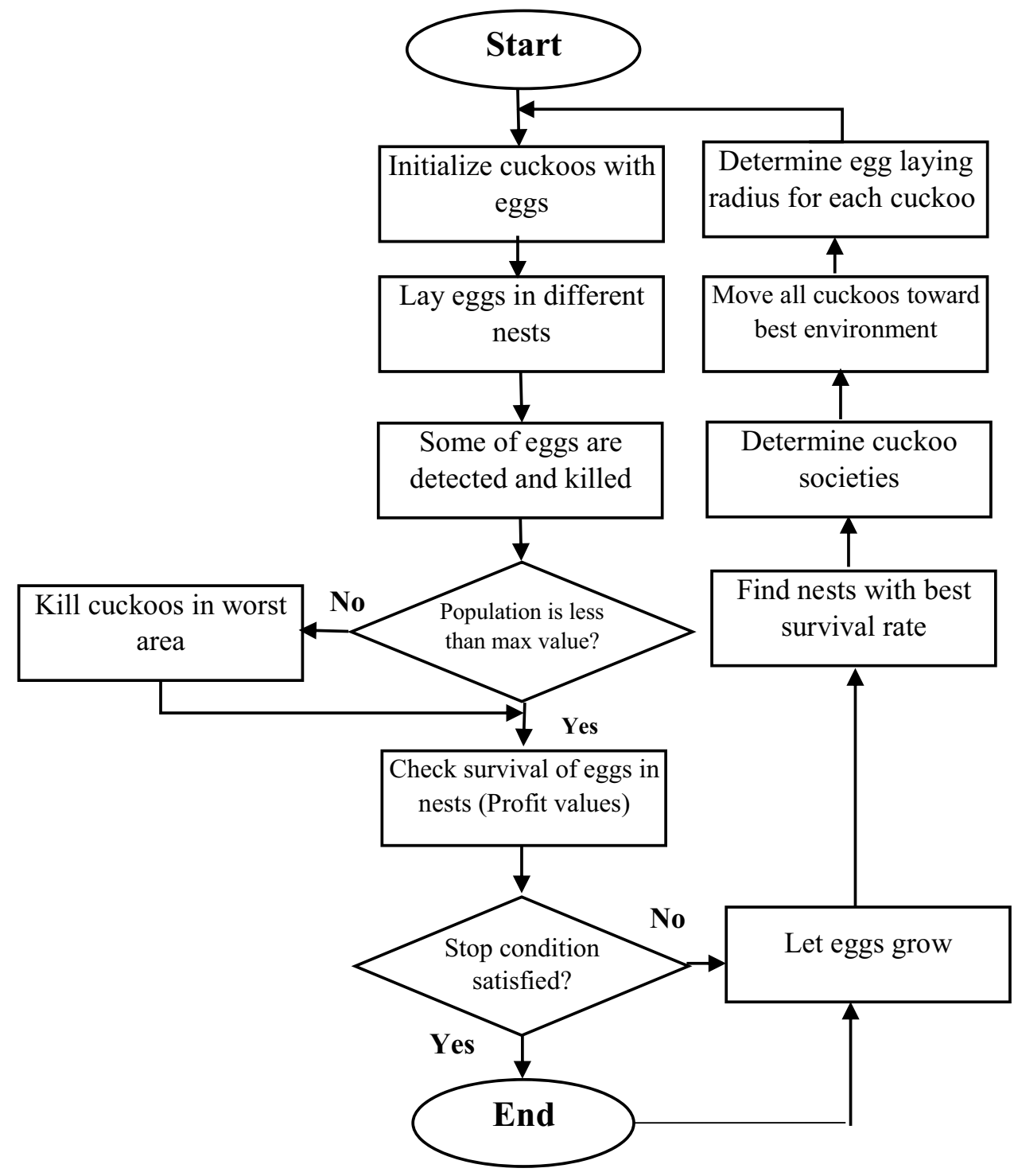

\section{Introducing the proposed DSM method}

In most real-world problems, we have more than one response or output and optimizing multiple responses at the same time is one of the major problems in problems. Through design of experiments of data, the response surfaces is obtained, which is an equation between a response variable and independent (input) variables. In such cases, it is difficult to optimize several response surfaces simultaneously in order to obtain the best independent variables. Various methods have been proposed to solve such problems, which include constraining the problem using other objectives, the utility function, and the least-cost response surface. Since the proposed method includes two methods DEA and RSM, it is called DSM method. This proposed algorithm combines the RSM as one of the optimization methods. In order to make the optimization process more efficient, in addition to the RSM, the DEA method has been used and a hybrid model of both is presented. The main advantage of the DSM algorithm is to create an efficiency surface instead of generating multiple surfaces for each of the output or objective functions. In DSM algorithm, first, a suitable experimental design is selected to generate the experiments, then the simulation process is performed for the designed experiments and the inputs and outputs generated from the simulation are analyzed using DEA and RSM tools. Finally, using the surface obtained for efficiency, the input parameters of the system can be determined in such a way that the system under review has the highest value of efficiency, and according to these input values, the corresponding outputs can be output from the response surfaces obtained for each output. The main advantage of the proposed model is its applicability to an unlimited number of objective functions and simultaneous attention to efficiency maximization along with optimization of problem outputs. The DSM method steps 
include design of experiment, data normalization, DEA model (for efficiency), and RSM model (for response efficiency). Also, the pseudo-code of this method is as follows:

1. Design of experiment or data collection: Control factors and response variables of problem are determined.

2. Data normalization: To reduce the effect of different scales on the data, the collected data have been normalized.

3. Determination of efficiency for each experiment by DEA: Using the input and output values of step 2, the efficiency value of each experiment is calculated.

4. Making efficiency surface by RSM: Using the input values of step 2 and the efficiency values obtained from step 3 , an efficient surface is creased using the RSM.

5. Calculate optimal inputs: The optimal values of input variables or control factors are obtained.

6. Calculate optimal outputs: The optimal values of outputs variables or responses are obtained.

Input and output variables are determined by previous research and expert opinion. This data is collected for a number of specific decision-making units. Normalizations are performed to reduce the effect of different scales on the data. In this study, the Euclidean norm mentioned in Eq. 3 is used.

$y^{\prime} i j=\frac{y_{i j}}{\sqrt{\sum_{j}^{n} y_{i j}^{2}}}$

Measuring the efficiency in the field of performance evaluation in companies and organizations is very important. DEA is a non-parametric method in performance evaluation. There are several models in the field of DEA. The CCR method in model 4 is a basic model that is used in this study to evaluate the efficiency of decision-making units.

$\operatorname{Max} \mathrm{E}_{u}=\frac{\sum_{y} u_{y} o_{t y}}{\sum_{x} u_{x} I_{t x}}$

\section{S.t.}

$$
\begin{gathered}
\frac{\sum_{y} u_{y} o_{w y}}{\sum_{x} u_{x} I_{w x}}<1 \\
w=1, \ldots, L, u_{y}>0, u_{x}>0
\end{gathered}
$$

The purpose of using the RSM (Eq. 5) is to determine the best variables (inputs) that can create the best values for the objective function (system output). The main advantage of the proposed method is in this section. In fact, instead of generating multiple response surfaces for the outputs separately, an efficiency surface according to Eq. 5 is presented to calculate the optimal level of parameters.
Max efficiency $=f(x)$

In fact, to construct the efficiency surface, we use normalized inputs as independent variables, as well as the functions calculated as response variables. After setting the efficiency surface by the Minitab software, the surface is optimized by the Lingo software, and we introduce the resulting solutions as optimal system inputs. It then sets a separate surface for each output, except that here each output is placed as a response variable. Then, the optimal independent variables are placed in the response surfaces, and the optimal response variables are obtained which are considered as the optimal outputs of the system.

\section{Parameter setting of COA using the proposed DSM hybrid method}

In this section, in order to investigate the proposed DSM method, the optimal parameters of the COA are set. The details of the implementation of the proposed approach for setting the algorithm parameter are shown in Fig. 2.

\section{Implement the proposed DSM method for standard functions}

The Ackley and Rastrigin functions are common non-convex functions used as a performance test problem for optimization algorithms. These functions are typical examples of non-linear multimodal functions. The Ackley function was proposed by David Ackley in his 1987 PhD Dissertation (Ackley 1987). Also, the Rastrigin function was presented in 1974 by Rastrigin as a 2-dimensional function (Rastrigin, 1974) and has been expended by Rudolph (Rudolph, 1990). The Ackley and Rastrigin functions are expressed as relations 6 and 7, respectively. Also, the diagrams of the Ackley and Rastrigin functions are shown in Fig. 3. As can be seen, these functions have many local minimum, and therefore, it is difficult to find the global minimum. However, the cuckoo algorithm can find as well the optimal solution for these two functions. Also, $n$ indicates the number of variables or dimensions of the problem, which is equal to 2 in Fig. 3, but we consider 100 to implement the DSM method and set the parameter.

$\operatorname{Min} F(x)=-20 \exp \left(-0.2 \sqrt{\frac{1}{n} \sum_{i=1}^{n} x_{i}^{2}}\right)-\exp \left(\frac{1}{n} \sum_{i=1}^{n} \cos \left(2 \pi . x_{i}\right)\right)+20+e$

$\operatorname{Min} F(x)=A n+\sum_{i=1}^{n}\left[x_{i}^{2}-A \cos \left(2 \pi x_{i}\right)\right]$ 
Fig. 2 Diagram of the DSM method to parameter setting meta-heuristic algorithms
Determining the input and output parameters for the desired metaheuristic algorithm (input variables)

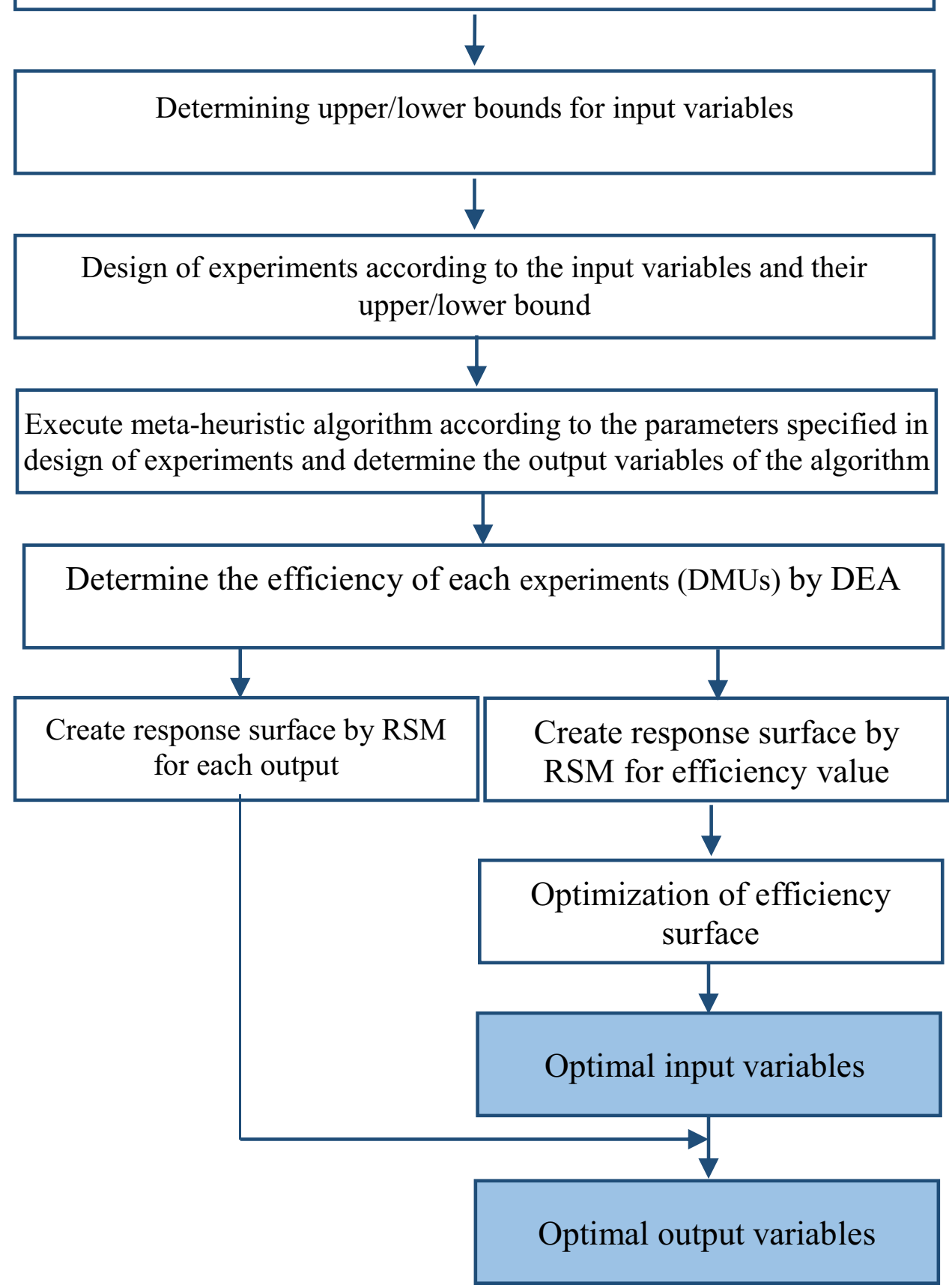

\section{Step 1: Determine the problem variables}

In this step, the independent variables (inputs) of the COA, which are the parameters of the algorithm, are determined, which are as follows:

1. The number of initial cuckoos (5-20)

2. The minimum number of eggs (2-4)
3. The maximum number of eggs (3-5)

4. Number of clusters (2-5)

5. Maximum number of cuckoos in each repetition (10-50)

The response variables (outputs) are as follows:

1. The value of the problem objective function

2. Execution time to solve the problem 


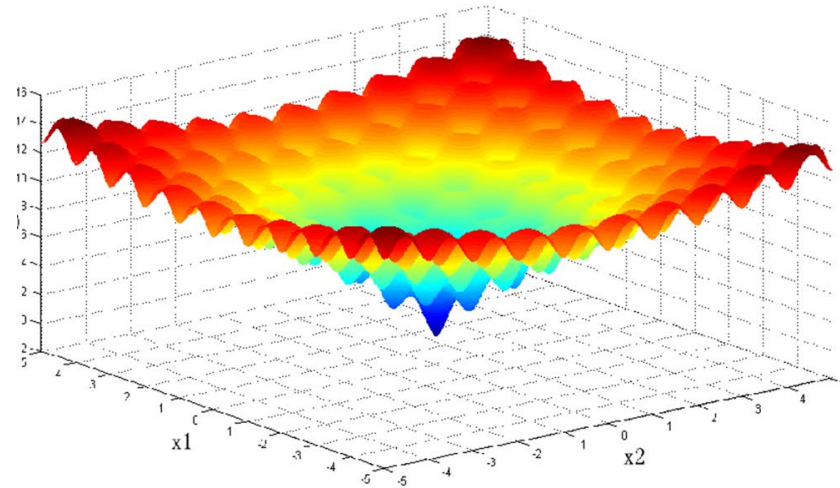

(a)

Fig. 3 The diagrams of functions. a Ackley. b Rastrigin

3. Number of iteration to solve the problem

\section{Step 2: Design of experiments}

By specifying the upper and lower bounds for each of the input variables (these bounds are written in front of the input parameters in parentheses), the design of experiments is performed using the Minitab software, the output of which is 32 test designs. In fact, each experiment is a configuration for the parameters of the meta-heuristic algorithm and consider as a DMU. Then, by placing each of these configurations of parameters in the COA, the optimization of Ackley and Rastrigin functions is performed with a number of variables equal to 100 , and the values of the output variables determined in the previous step are measured, and the results for Ackley and Rastrigin functions are shown in Table 3.

\section{Step 3: Data normalization}

According to previous statements, the data are normalized with Euclidean norm. It should be noted that the type of the outputs values are cost, and Eq. 6 is used to normalize them (Eq. 8).

$y_{i}^{\prime}=1-\left(\frac{y_{i}}{\sum_{i=1}^{n} y_{i}^{2}}\right)$

\section{Step 4: Calculate efficiency by DEA}

Each of the experiments or configurations of the previous step is considered as a DMU, and the efficiency values for each algorithm configuration in both functions are calculated using the DEA method and Lingo software according to last columns of Table 3. The calculation of efficiency values is done with the CCR approach.

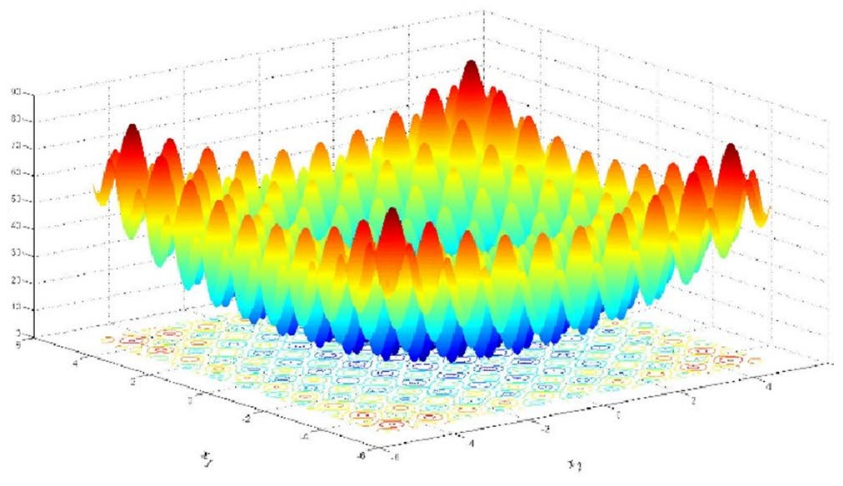

(b)

\section{Step 5: Efficiency surface and response surfaces by RSM model}

In this step, using the information obtained from steps 4 and 5 , the surfaces for efficiency and output variables are constructed. Surfaces are created using the Minitab software, inputs are considered as independent variables, and efficiency calculated in step 5 is considered as a response or dependent variable. The efficiency surface for the Ackley and Rastrigin functions is in accordance with Eqs. 9 and 10.

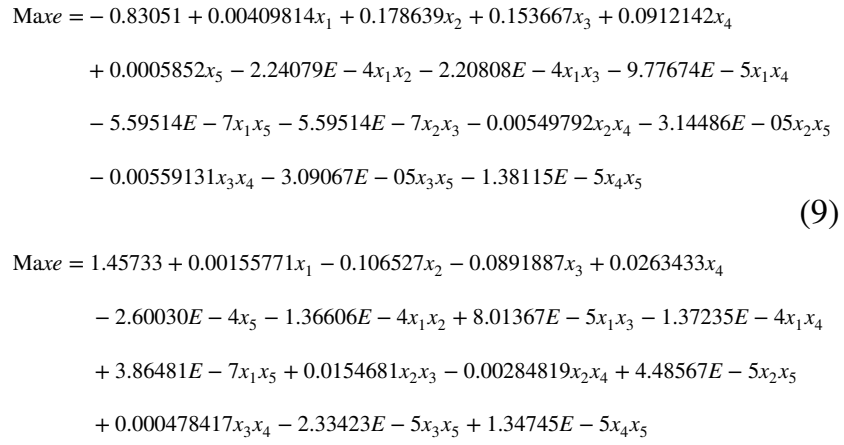

Maxe $=1.45733+0.00155771 x_{1}-0.106527 x_{2}-0.0891887 x_{3}+0.0263433 x_{4}$

$$
\begin{aligned}
& -2.60030 E-4 x_{5}-1.36606 E-4 x_{1} x_{2}+8.01367 E-5 x_{1} x_{3}-1.37235 E-4 x_{1} x_{4} \\
& +3.86481 E-7 x_{1} x_{5}+0.0154681 x_{2} x_{3}-0.00284819 x_{2} x_{4}+4.48567 E-5 x_{2} x_{5} \\
& +0.000478417 x_{3} x_{4}-2.33423 E-5 x_{3} x_{5}+1.34745 E-5 x_{4} x_{5}
\end{aligned}
$$

Also, for the three mentioned outputs, separate procedures are considered in which the inputs are considered as independent variables and the outputs as the response variable. The Ackley function response surfaces are in the form of relations 11,12 , and 13. Also, the response functions of the Rastrigin function are in the form of 14,15 , and 16 relations.

The objective function surface for the Ackley function $\left(y_{1}\right)$ is as follows:

$$
\begin{aligned}
y_{1}= & 2.87342+0.000230282 x_{1}+0.00919271 x_{2}+0.00825863 x_{3}+0.00982920 x_{4} \\
& +7.13368 E-06 x_{5}+1.82222 E-05 x_{1} x_{2}-4.05556 E-05 x_{1} x_{3}-1.10617 E-05 x_{1} x_{4} \\
& +7.80556 E-08 x_{1} x_{5}-2.75000 E-04 x_{2} x_{3}-0.00159722 x_{2} x_{4}+2.18750 E-06 x_{2} x_{5} \\
& +0.000227778 x_{3} x_{4}-4.23437 E-06 x_{3} x_{5}+3.33333 E-07 x_{4} x_{5}
\end{aligned}
$$


Table 3 The input and output values for the Ackley and Rastrigin functions

\begin{tabular}{|c|c|c|c|c|c|c|c|c|c|}
\hline \multirow{2}{*}{$\begin{array}{l}\text { Number of } \\
\text { experiment }\end{array}$} & \multicolumn{5}{|l|}{ Inputs } & \multicolumn{3}{|l|}{ Output } & \multirow[t]{2}{*}{ Efficiency } \\
\hline & $\begin{array}{l}\text { Number } \\
\text { of cuckoos }\end{array}$ & $\begin{array}{l}\text { Min } \\
\text { number of } \\
\text { eggs }\end{array}$ & $\begin{array}{l}\text { Max } \\
\text { number of } \\
\text { eggs }\end{array}$ & $\begin{array}{l}\text { Number } \\
\text { of clusters }\end{array}$ & $\begin{array}{l}\text { Maximum } \\
\text { number of } \\
\text { cuckoos }\end{array}$ & Objective function & Execution time & $\begin{array}{l}\text { Number of } \\
\text { iteration }\end{array}$ & \\
\hline \multicolumn{10}{|c|}{ Ackley function } \\
\hline 1 & 20 & 4 & 5 & 2 & 10 & 2.9914 & 0.948 & 18 & 0.99938 \\
\hline 2 & 20 & 2 & 3 & 2 & 50 & 2.9838 & 1.107 & 18 & 1 \\
\hline 3 & 5 & 2 & 3 & 5 & 50 & 2.9879 & 1.067 & 17 & 0.99982 \\
\hline 4 & 20 & 4 & 3 & 5 & 50 & 2.986 & 1.413 & 16 & 1 \\
\hline 5 & 5 & 4 & 3 & 5 & 50 & 2.9856 & 0.941 & 17 & 1 \\
\hline 6 & 5 & 4 & 3 & 2 & 10 & 2.9863 & 0.92 & 17 & 1 \\
\hline 7 & 20 & 4 & 3 & 2 & 50 & 2.9847 & 1.33 & 18 & 0.999871 \\
\hline 8 & 20 & 4 & 3 & 2 & 10 & 2.9829 & 0.925 & 16 & 1 \\
\hline 9 & 20 & 4 & 5 & 5 & 10 & 2.9839 & 0.966 & 17 & 0.999871 \\
\hline 10 & 20 & 4 & 5 & 5 & 50 & 2.985 & 1.806 & 17 & 0.5999 \\
\hline 11 & 5 & 2 & 3 & 2 & 50 & 2.9852 & 1.026 & 17 & 1 \\
\hline 12 & 20 & 2 & 3 & 5 & 50 & 3.0095 & 1.195 & 16 & 1 \\
\hline 13 & 20 & 2 & 3 & 2 & 10 & 2.9904 & 0.934 & 17 & 1 \\
\hline 14 & 5 & 2 & 5 & 2 & 10 & 2.9855 & 0.907 & 17 & 1 \\
\hline 15 & 5 & 4 & 5 & 5 & 10 & 2.9861 & 0.935 & 17 & 0.99996 \\
\hline 16 & 5 & 2 & 3 & 5 & 10 & 2.9984 & 0.91 & 16 & 1 \\
\hline 17 & 5 & 2 & 5 & 5 & 50 & 3.001 & 1.316 & 16 & 1 \\
\hline 18 & 5 & 2 & 3 & 2 & 10 & 2.9878 & 0.925 & 17 & 1 \\
\hline 19 & 5 & 4 & 3 & 2 & 50 & 2.985 & 1.244 & 18 & 1 \\
\hline 20 & 5 & 2 & 5 & 5 & 10 & 3.0337 & 0.934 & 19 & 0.996539 \\
\hline 21 & 5 & 4 & 3 & 5 & 10 & 2.982 & 0.911 & 18 & 1 \\
\hline 22 & 20 & 2 & 5 & 2 & 50 & 2.986 & 1.313 & 18 & 0.999843 \\
\hline 23 & 5 & 4 & 5 & 5 & 50 & 2.9858 & 1.653 & 18 & 0.999733 \\
\hline 24 & 20 & 2 & 5 & 5 & 10 & 2.9877 & 0.922 & 17 & 0.999853 \\
\hline 25 & 20 & 4 & 5 & 2 & 50 & 2.983 & 1.614 & 17 & 0.9999 \\
\hline 26 & 5 & 4 & 5 & 2 & 50 & 2.9897 & 1.6 & 17 & 1 \\
\hline 27 & 5 & 2 & 5 & 2 & 50 & 2.9875 & 1.236 & 18 & 0.999835 \\
\hline 28 & 20 & 2 & 5 & 5 & 50 & 2.9886 & 1.428 & 17 & 0.999773 \\
\hline 29 & 20 & 2 & 3 & 5 & 10 & 2.986 & 0.928 & 17 & 1 \\
\hline 30 & 20 & 4 & 3 & 5 & 10 & 2.9822 & 0.946 & 16 & 1 \\
\hline 31 & 20 & 2 & 5 & 2 & 10 & 2.9894 & 0.937 & 18 & 0.99972 \\
\hline 32 & 5 & 4 & 5 & 2 & 10 & 2.9914 & 0.917 & 18 & 0.999576 \\
\hline \multicolumn{10}{|c|}{ Rastrigin function } \\
\hline 1 & 20 & 4 & 5 & 2 & 50 & 3.1538 & 1.712 & 34 & 1 \\
\hline 2 & 5 & 2 & 3 & 5 & 10 & 2.6724 & 0.98 & 34 & 1 \\
\hline 3 & 5 & 2 & 5 & 2 & 10 & 3.3072 & 0.962 & 34 & 1 \\
\hline 4 & 5 & 4 & 3 & 5 & 10 & 0.35279 & 0.945 & 31 & 1 \\
\hline 5 & 5 & 4 & 3 & 5 & 50 & 19.3691 & 1.267 & 37 & 1 \\
\hline 6 & 20 & 2 & 5 & 5 & 50 & 2.9032 & 1.333 & 35 & 1 \\
\hline 7 & 5 & 2 & 3 & 5 & 50 & 22.6083 & 1.114 & 33 & 0.916667 \\
\hline 8 & 20 & 2 & 5 & 2 & 10 & 12.2647 & 0.916 & 35 & 1 \\
\hline 9 & 20 & 4 & 5 & 5 & 10 & 2.6991 & 0.972 & 36 & 0.989076 \\
\hline 10 & 5 & 2 & 5 & 2 & 50 & 5.4416 & 1.232 & 36 & 0.628767 \\
\hline 11 & 5 & 4 & 5 & 2 & 50 & 32.8557 & 1.552 & 34 & 1 \\
\hline 12 & 5 & 4 & 5 & 5 & 10 & 6.5067 & 0.97 & 30 & 0.946179 \\
\hline 13 & 5 & 2 & 5 & 5 & 50 & 7.813 & 1.229 & 32 & 1 \\
\hline
\end{tabular}


Table 3 (continued)

\begin{tabular}{|c|c|c|c|c|c|c|c|c|c|}
\hline \multirow{2}{*}{$\begin{array}{l}\text { Number of } \\
\text { experiment }\end{array}$} & \multicolumn{5}{|l|}{ Inputs } & \multicolumn{3}{|l|}{ Output } & \multirow[t]{2}{*}{ Efficiency } \\
\hline & $\begin{array}{l}\text { Number } \\
\text { of cuckoos }\end{array}$ & $\begin{array}{l}\text { Min } \\
\text { number of } \\
\text { eggs }\end{array}$ & $\begin{array}{l}\text { Max } \\
\text { number of } \\
\text { eggs }\end{array}$ & $\begin{array}{l}\text { Number } \\
\text { of clusters }\end{array}$ & $\begin{array}{l}\text { Maximum } \\
\text { number of } \\
\text { cuckoos }\end{array}$ & Objective function & Execution time & $\begin{array}{l}\text { Number of } \\
\text { iteration }\end{array}$ & \\
\hline 14 & 20 & 4 & 5 & 2 & 10 & 5.3067 & 1.125 & 33 & 1 \\
\hline 15 & 20 & 4 & 3 & 2 & 50 & 2.3753 & 1.233 & 38 & 1 \\
\hline 16 & 20 & 2 & 3 & 5 & 50 & 4.6461 & 1.138 & 34 & 1 \\
\hline 17 & 20 & 4 & 3 & 5 & 50 & 14.716 & 1.289 & 34 & 0.9967 \\
\hline 18 & 20 & 2 & 5 & 5 & 10 & 13.8605 & 1.045 & 30 & 1 \\
\hline 19 & 20 & 2 & 5 & 2 & 50 & 1.1338 & 1.293 & 36 & 1 \\
\hline 20 & 20 & 4 & 3 & 5 & 10 & 9.0523 & 0.942 & 32 & 0.941176 \\
\hline 21 & 5 & 2 & 3 & 2 & 10 & 18.366 & 0.92 & 33 & 0.942857 \\
\hline 22 & 5 & 4 & 5 & 5 & 50 & 14.0465 & 1.621 & 37 & 1 \\
\hline 23 & 5 & 2 & 5 & 5 & 10 & 3.0532 & 0.922 & 33 & 0.962345 \\
\hline 24 & 20 & 4 & 3 & 2 & 10 & 12.3225 & 0.952 & 43 & 1 \\
\hline 25 & 20 & 2 & 3 & 5 & 10 & 0.116 & 1.265 & 32 & 1 \\
\hline 26 & 20 & 2 & 3 & 2 & 50 & 4.4028 & 1.24 & 33 & 0.953243 \\
\hline 27 & 20 & 2 & 3 & 2 & 10 & 0.6687 & 1.097 & 36 & 1 \\
\hline 28 & 5 & 4 & 3 & 2 & 10 & 19.591 & 1.145 & 32 & 0.838342 \\
\hline 29 & 5 & 4 & 5 & 2 & 10 & 7.224 & 1.042 & 35 & 1 \\
\hline 30 & 20 & 4 & 5 & 5 & 50 & 1.053 & 1.83 & 32 & 1 \\
\hline 31 & 5 & 2 & 3 & 2 & 50 & 1.9087 & 1.136 & 32 & 1 \\
\hline 32 & 5 & 4 & 3 & 2 & 50 & 9.9196 & 1.1409 & 31 & 0.885714 \\
\hline
\end{tabular}

The time execution surface for the Ackley function $\left(y_{2}\right)$ :

$$
\begin{aligned}
y_{1}= & 3.19427-9.64494 E-04 x_{1}-0.248918 x_{2}-0.260315 x_{3}+0.00982920 x_{4} \\
& -0.00220977 x_{5}+0.000213333 x_{1} x_{2}-2.21111 E-04 x_{1} x_{3}+0.000149136 x_{1} x_{4} \\
& +1.35556 E-06 x_{1} x_{5}+0.0283750 x_{2} x_{3}-0.00336111 x_{2} x_{4}+0.000143906 x_{2} x_{5} \\
& +0.00816667 x_{3} x_{4}+0.000201250 x_{3} x_{5}+1.07639 E-05 x_{4} x_{5}
\end{aligned}
$$

The number of iteration surface for the Ackley function $\left(y_{3}\right)$ :

$$
\begin{aligned}
y_{3}= & 11.5064+0.0201019 x_{1}+0.512674 x_{2}+0.559201 x_{3}-0.211343 x_{4} \\
& +0.00434028 x_{5}-0.00333333 x_{1} x_{2}+0.00111111 x_{1} x_{3}-0.00148148 x_{1} x_{4} \\
& +2.77778 E-06 x_{5}-0.0625000 x_{2} x_{3}+0.0277778 x_{2} x_{4}+0.000156250 x_{2} x_{5} \\
& +0.0277778 x_{3} x_{4}-4.68750 E-04 x_{3} x_{5}-2.08333 E-04 x_{4} x_{5}
\end{aligned}
$$

The objective function surface for the Rastrigin function $\left(y_{1}\right)$ :

$Y_{1}=38.5052+0.0296916 x_{1}+8.45343 x_{2}+3.47633 x_{3}+3.01223 x_{4}$

$$
\begin{aligned}
& -0.0229248 x_{5}-0.0188956 x_{1} x_{2}+0.00478616 x_{1} x_{3}+0.00731104 x_{1} x_{4} \\
& -1.03883 E-04 x_{1} x_{5}-0.288790 x_{2} x_{3}-0.487949 x_{2} x_{4}+0.00295977 x_{2} x_{5} \\
& -0.315704 x_{3} x_{4}-2.05134 E-04 x_{3} x_{5}+0.00231603 x_{4} x_{5}
\end{aligned}
$$

The time execution surface for the Rastrigin function $\left(y_{2}\right)$ :
$Y_{2}=4.26218+0.000353820 x_{1}-0.439723 x_{2}-0.426627 x_{3}+0.00826078 x_{4}$

$$
\begin{aligned}
& -0.00226608 x_{5}-2.55500 E-04 x_{1} x_{2}+0.000104389 x_{1} x_{3}+8.09630 E-05 x_{1} x_{4} \\
& +4.83472 E-07 x_{1} x_{5}+0.0583781 x_{2} x_{3}-0.00410972 x_{2} x_{4}+0.000151867 x_{2} x_{5} \\
& +0.000165278 x_{3} x_{4}+0.000198133 x_{3} x_{5}+1.38924 E-05 x_{4} x_{5}
\end{aligned}
$$

The number of iteration surface for the Rastrigin function $\left(y_{3}\right)$ :

$$
\begin{aligned}
Y_{3}= & 14.7940+0.117650 x_{1}+2.27370 x_{2}+2.67040 x_{3}-0.191397 x_{4} \\
& -0.0120052 x_{5}+0.0061111 x_{1} x_{2}-0.0105556 x_{1} x_{3}-0.00567901 x_{1} x_{4} \\
& -1.52778 E-05 x_{1} x_{5}-0.343750 x_{2} x_{3}+0.0138889 x_{2} x_{4}+7.81250 E-05 x_{2} x_{5} \\
& -0.0138889 x_{3} x_{4}+0.000859375 x_{3} x_{5}+0.000798611 x_{4} x_{5}
\end{aligned}
$$

\section{Step 6: Optimize efficiency surfaces and response surfaces}

To find the optimal parameters of the COA, the surfaces obtained for efficiency (Eqs. 7 and 128 are optimized with Lingo software and the values of the independent variables are determined in Table 4 (Input).

Then, to calculate the values of the corresponding response variables, the obtained values of the independent 
Table 4 The optimal values of independent variables and responses from DSM method

\begin{tabular}{llll}
\hline Input & Independent variables & Optimal values of Ackley & Optimal values of Rastrigin \\
\hline Number of cuckoos & $X_{1}$ & $2.086 \approx 3$ & $1.234 \approx 2$ \\
Min number of eggs & $X_{2}$ & $4.58 \approx 4$ & $1.234 \approx 2$ \\
Max number of eggs & $X_{3}$ & $6.128 \approx 6$ & $5.1167 \approx 5$ \\
Number of clusters & $X_{4}$ & $2.08 \approx 2$ & $1.234 \approx 1$ \\
Maximum number of cuckoos & $X_{5}$ & $1.2 \approx 2$ & $1.234 \approx 2$ \\
Output & Response variables & Optimal values of Ackley & Optimal values of Rastrigin \\
Objective function & $Y 1$ & 2.966 & 65.9 \\
Execution time & $Y 2$ & 1.2 & 1.05 \\
Number of iterations & $Y 3$ & $15.72 \approx 16$ & $10.1 \approx 10$ \\
\hline
\end{tabular}

variables (input of Table 4) are placed in the output surfaces and the values of the response variables are calculated according to Table 4 (output).

\section{Validation of the proposed DSM method compared to similar approaches}

In this section, the proposed DSM method is compared with similar methods through different approaches including numerical results, Najafi and Behnoud (2015) method, Taguchi method and general comparison of all methods.

\section{Comparison of analytical and numerical results of DSM method (validation I)}

In this step, using the optimal configuration obtained from the proposed algorithm of the paper, the COA is executed 10 times with the help of the MATLAB software. This process is performed separately for both the Ackley and Rastrigin functions. It should be noted that because the independent variables (inputs) must be integers, the previously obtained optimal variables are rounded out according to Table 4. After executing the COA, the average of each response variable is calculated in Table 5. This process is to validate the results of the proposed DSM method with the results of the actual implementation of the algorithm. In fact, the results of the analytical approach are compared with numerical results. To facilitate the comparison of the results of both methods, the absolute value of the difference of the response variables in both approaches is calculated according to last column of Table 5.

As can be seen, the difference between the optimal values obtained from the DSM method and the values obtained from the implementation of the algorithm is very small, and this indicates the optimality of the proposed DSM method.

\section{Comparison of numerical and analytical results of the Najafi and Behnoud method (validation II)}

In this section, the results of the proposed method are compared with the method of Najafi and Behnoud (2015) that were observed in the literature review. In this method, first, a central composite design was created, and then using the data related to this design, the complete second-order model was fitted. Then the optimal values of the parameters are determined by solving the non-linear model. Then, the efficiency of the problems solved by the algorithm is measured by considering the obtained parameters as inputs of the DEA method and the most efficient configuration of the genetic algorithm is determined. In this section, in order to validate the proposed DSM method, Najafi and Behnoud's (2015) method are implemented for the Ackley and Rastrigin functions. As can be seen from the process of this method, the algorithm parameter setting dose only pays attention to the response value of the objective function, and other important outputs such as execution time and number of iterations are not considered. The process of the Najafi and Behnoud (2015) methods are as follows.

\section{Step 1: Determine the problem variables}

Input variables (parameters affecting the performance of the algorithm) are identified, which are the same as input variables of the DSM method. Also, the output is the value of the objective function of the problem. Unlike the proposed DSM method, only one response is considered that is the value of the objective function of the problem, and the execution time and number of iterations are ignored. 
Table 5 Tables of validation of the proposed DSM method compared to similar approaches

Comparison of numerical and analytical results from DSM method

\begin{tabular}{|c|c|c|c|c|c|}
\hline Function & Response variables & DSM method (analytical) & $\begin{array}{l}\text { Algorithm execution (numeri- } \\
\text { cal) }\end{array}$ & Difference & \\
\hline \multirow[t]{3}{*}{ Ackley } & $Y_{1}$ & 2.966 & 2.9932 & 0.0272 & \\
\hline & $Y_{2}$ & 1.2 & 0.9291 & 0.16 & \\
\hline & $Y_{3}$ & 16 & 18 & 2 & \\
\hline \multirow[t]{3}{*}{ Rastrigin } & $Y_{1}$ & 65.9 & 43.85 & 22.05 & \\
\hline & $Y_{2}$ & 1.9 & 0.89 & 1.01 & \\
\hline & $Y_{3}$ & 29 & 30 & 1 & \\
\hline \multicolumn{6}{|c|}{ The optimal values of independent variables and responses from Najafi and Behnoud method } \\
\hline Input & Independent variables & Ackley function & Rastrigin function & & \\
\hline Number of cuckoos & $X_{1}$ & 20 & 5 & & \\
\hline Min number of eggs & $X_{2}$ & 2 & 2 & & \\
\hline Max number of eggs & $X_{3}$ & 3 & 3 & & \\
\hline Number of clusters & $X_{4}$ & 2 & 2 & & \\
\hline Maximum number of cuckoos & $X_{5}$ & 50 & 50 & & \\
\hline Output & Response variables & Ackley function & Rastrigin function & & \\
\hline Objective function & $Y 1$ & 2.657 & 65.71 & & \\
\hline Execution time & $Y 2$ & 1.91 & 2.38 & & \\
\hline Number of iteration & $Y 3$ & 14.10 & 24.9 & & \\
\hline \multicolumn{6}{|c|}{ Comparison of numerical and analytical results from Najafi and Behnoud method } \\
\hline Function & Output & Response variables & $\begin{array}{l}\text { Najafi and Behnoud method } \\
\text { (analytical) }\end{array}$ & $\begin{array}{l}\text { Algorithm } \\
\text { execution } \\
\text { (numerical) }\end{array}$ & Difference \\
\hline \multirow[t]{3}{*}{ Ackley } & Objective function & $Y_{1}$ & 2.657 & 2.96 & 0.303 \\
\hline & Execution time & $Y_{2}$ & 19.1 & 1.36 & 17.74 \\
\hline & Number of iteration & $Y_{3}$ & 14 & 17 & 3 \\
\hline \multirow[t]{3}{*}{ Rasrtigin } & Objective function & $Y_{1}$ & 65.71 & 8.1456 & 57.56 \\
\hline & Execution time & $Y_{2}$ & 2.38 & 1.04 & 1.34 \\
\hline & Number of iteration & $Y_{3}$ & 25 & 34 & 9 \\
\hline
\end{tabular}

\section{Step 2: Calculate the values of the variables}

The values of the inputs and the corresponding value of the objective function are determined for the COA similar to the DSM method (Table 3).

\section{Step 3: Surface of objective function by RSM}

In order to implement the RSM method for the step 2 data, the response surface is created according to the values of the inputs for the output of the value of the objective function. Similarly, the response surface is the value of the objective function for the Ackley and Rastrigin functions according to Eqs. 9 and 12.

\section{Step 4: Optimization of objective function surface}

In order to determine the input parameters, the response surface of the value of the objective function (Eqs. 9 and 12) is considered, and the constraints related to the boundaries of the parameters of meta-heuristic are considered. Finally, the mathematical model of parameter setting related to the Ackley and Rastrigin functions is 17 and 18, respectively. These models are optimized with the Lingo software, and the optimal values obtained for both functions are shown in Table 5 (input).

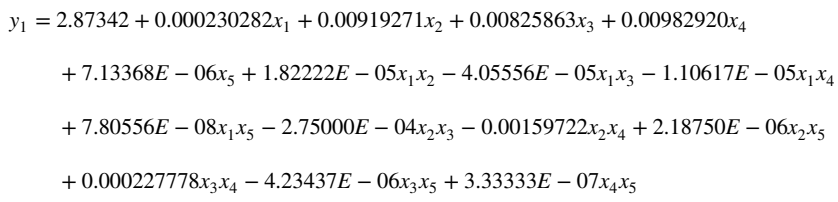

S.t.

$5 \leq x_{1} \leq 20$

$2 \leq x_{2} \leq 4$

$3 \leq x_{3} \leq 5$

$2 \leq x_{4} \leq 5$

$10 \leq x_{5} \leq 50$ 


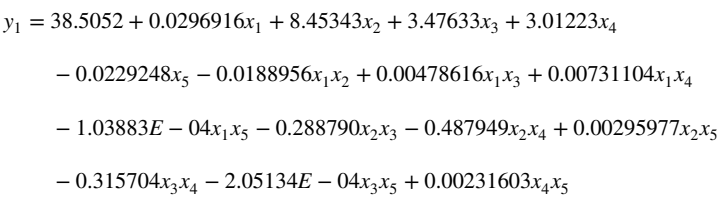

S.t.

$10 \leq x_{5} \leq 50$

$5 \leq x_{1} \leq 20$

$2 \leq x_{2} \leq 4$

$3 \leq x_{3} \leq 5$

$2 \leq x_{4} \leq 5$

$10 \leq x_{5} \leq 50$

The optimal values obtained for the COA parameters are placed in the response surfaces (Eqs. 11, 12, 13, 14, 15, and 16), and the values are calculated according to Table 5 (output).

\section{Step 5: Comparison of the results}

In this step, using the input variables obtained in step 4, the COA for both the Ackley and Rastrigin functions, with the help of the MATLAB software, is executed 10 times, and the average of the obtained response variables (numerical) to compare with the result obtained in step 4 (analytical). For ease of comparison, the absolute value of the difference in the results is calculated in Table 5. According to the results, it can be seen that Najafi and Behnoud's (2015) methods have a big difference in terms of numerical and analytical, while in the proposed method (Table 5), this difference was small.

\section{Comparison of the results of the Taguchi method with DSM (validation III)}

As mentioned in the literature review, one of the most common tools used to parameter setting of meta-heuristic algorithms is the Taguchi method. In the following, the Taguchi and RSM methods are implemented for both of the Ackley and Rastrigin functions, and for each function, responses are considered separately, and the results are shown in Fig. 4. As mentioned earlier, this method only optimizes one response. Figure 4 (a) shows that considering the response value of the objective function, the best values for the input parameters are $20,4,3,2$, and 50 . But if the execution time is examined (b), these optimal values change to 5, 2, 3, 2, and 10. Also, considering the results of response, the number of iterations (c) in Taguchi method are 20,2, 3, 2, and 10. According to the different results of Taguchi method, the DSM method is implemented and the efficiency response is considered (d). To determine the most important factor, RSM method was implemented, the results of which can be seen in Fig. 4. When the value of the objective function is considered as the response, the most important parameter is mini number of egg (e), and considering the execution time and the number of iterations as the response ( $\mathrm{f}$ and $\mathrm{g}$ ), the most important input variables will be maximum number of cuckoo and number of clusters, respectively. Here, too, the efficiency response is used because of the different results, and as can be seen (h), all inputs are of almost equal importance. This process is performed similarly for the Rastrigin function, and the results are shown in Fig. 4 (i-p).

\section{Comparison of DSM, Taguchi, and Najafi and Behnoud methods (validation IV)}

Figure 5 is based on the results obtained from the previous sections. As can be seen, the proposed DSM method performs better than other methods in all three responses of the value of the objective function, the execution time and the number of iterations of the algorithm. In the Ackley function, it was much better in terms of execution time, and in Rastrigin function, it was much better in terms of number of iteration. It should be noted that according to the different results of Taguchi method, the average of these values has been considered.

In order to compare the entire configuration created by the proposed DSM method with the Najafi and Behnoud and Taguchi methods in terms of both input and output values, the configuration efficiency obtained from the DSM method is compared with the configuration efficiency of other methods. The values for the DSM method, Najafi and Behnoud (2015) method, and Taghuchi on the Ackley function are, 45.3779, 3.64499, and 2.78653, respectively. Also for the Rastrigin function are 48.8649, 2.13645, and 2.03467. In order to better compare the three methods, we allow the DEA model to have an efficiency value of more than one. It can be seen that the configuration created by the DSM method in both Ackley and Rastrigin functions is more efficient than other methods, and this indicates the superiority of the DSM method. Due to the importance of parameter setting, the proposed method can be used in various problems such as repairs' scheduling (Al-Refaie \& AlHawadi, 2021), supply chain network design (Hasani et al., 2021; Hosnavi et al., 2019; Khalili et al., 2017), and vehicle routing (Khalili et al., 2016; Latorre-Biel et al., 2021).

\section{Implementation of the proposed DSM method for the inverse logistics problem of COVID-19 waste}

In this section, the reverse logistics model of COVID-19 waste presented by Shadkam (2021a, 2021b, 2021c) is reviewed. After describing the model, it will be optimized using the proposed method of DSM and cuckoo optimization algorithm. 


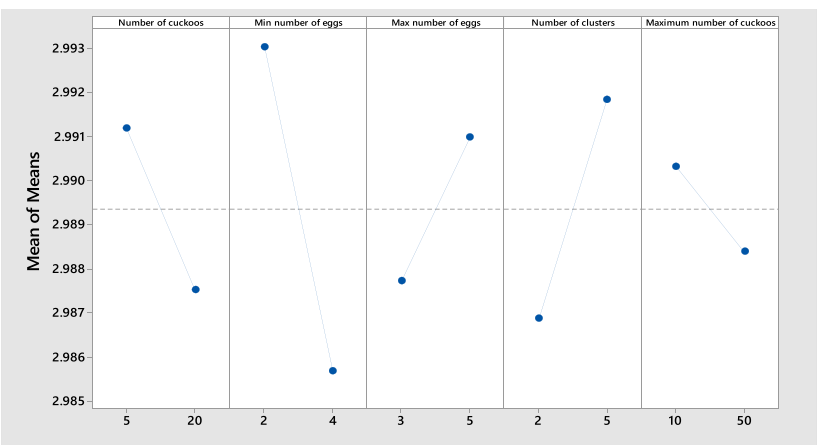

(a)

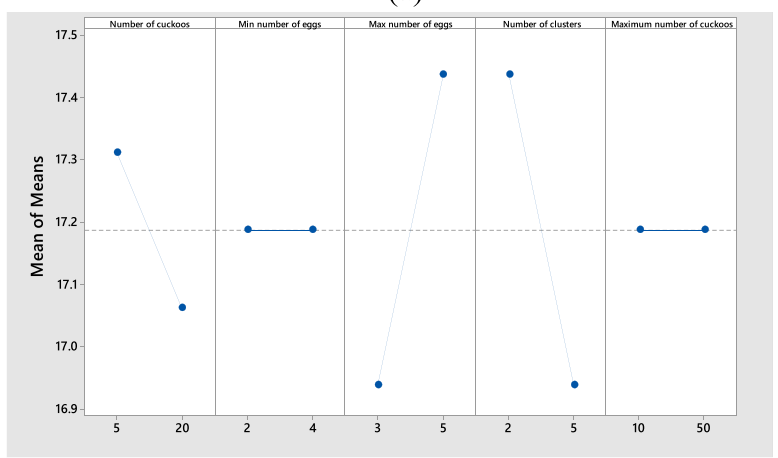

(c)

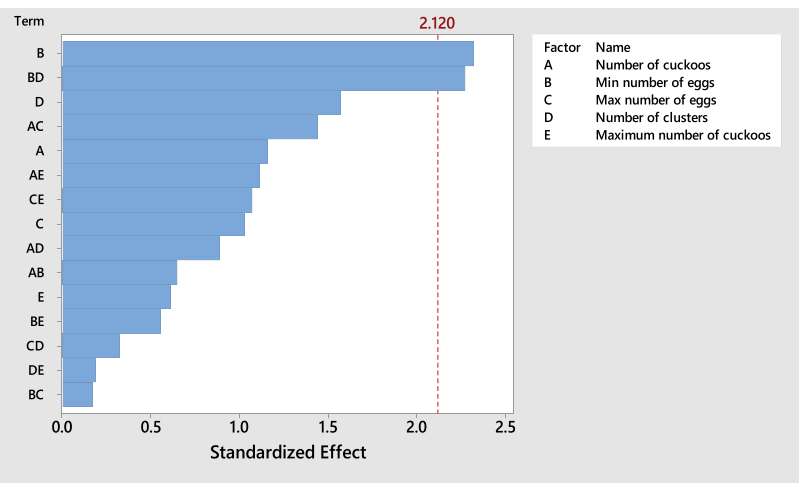

(e)

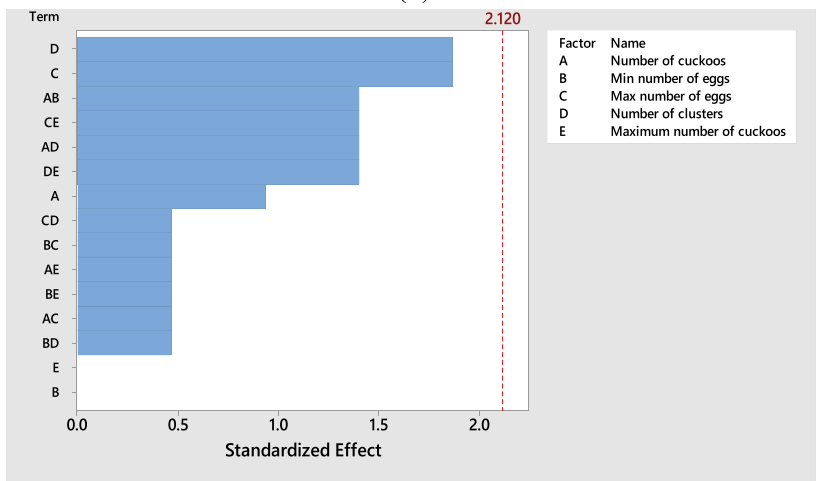

(g)

Fig. 4 The main effects plot for the means of the Ackley function. a Objective function. b Execution time. c Number of iterations. d Efficiency and Pareto chart of the standardized effects of the Ackley function. e Objective function. f Execution time. $\mathbf{g}$ Number of iterations. $\mathbf{h}$ Efficiency and main effects plot for the means of the Ras-

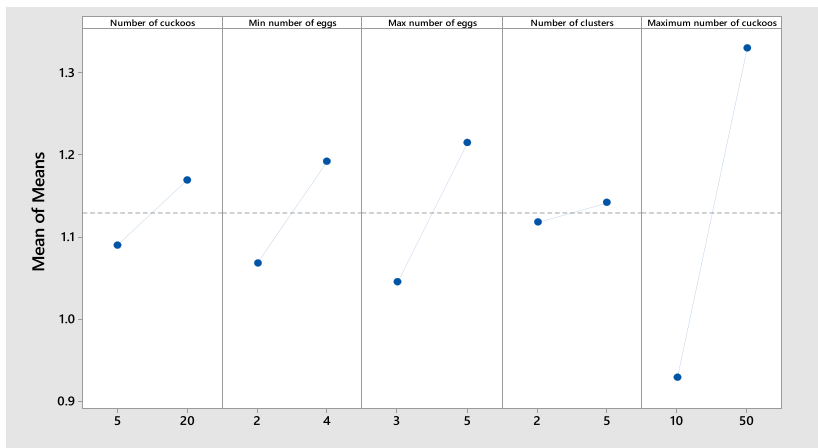

(b)

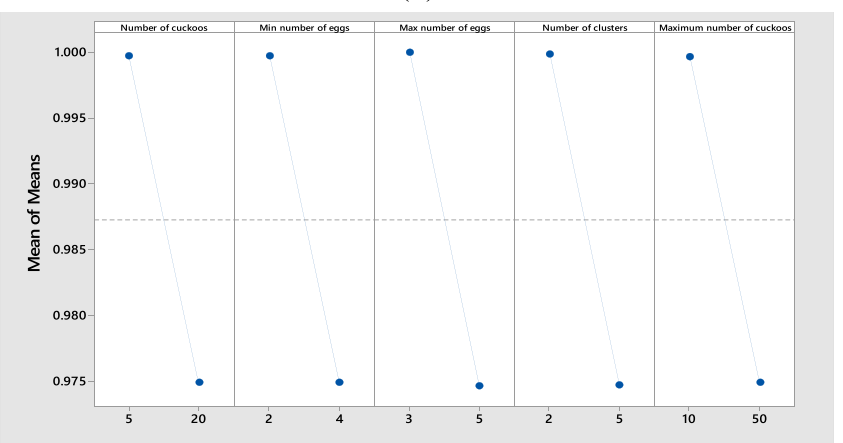

(d)

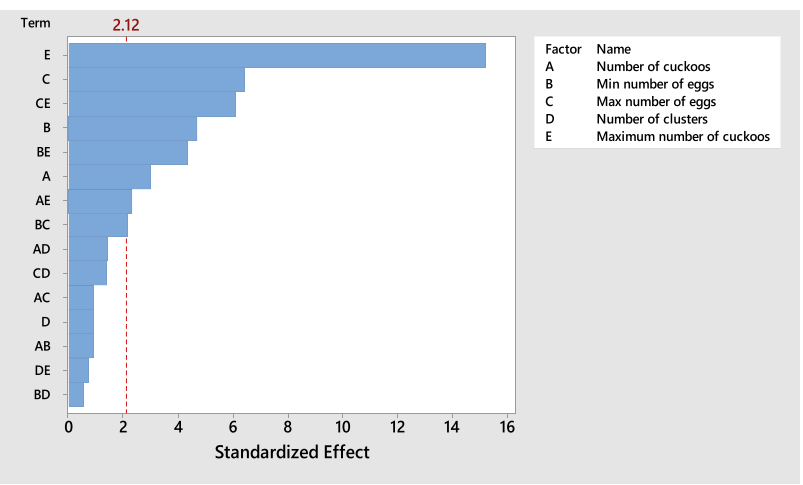

(f)

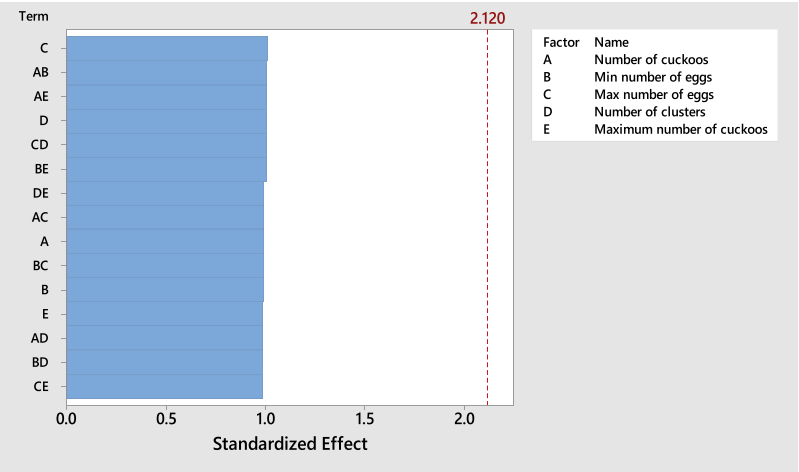

(h)

trigin function. i Objective function. $\mathbf{j}$ Execution time. $\mathbf{k}$ Number of iterations. 1 Efficiency and Pareto chart of the standardized effects of the Rastrigin function. $\mathbf{m}$ Objective function. $\mathbf{n}$ Execution time. o Number of iterations. p Efficiency 


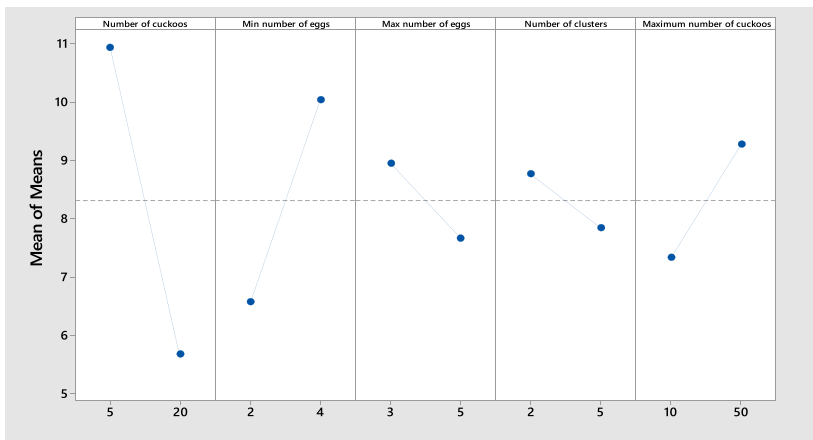

(i)

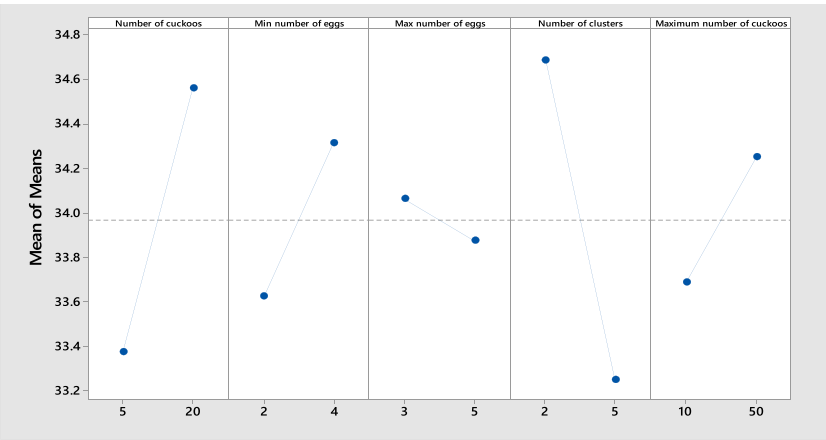

(k)

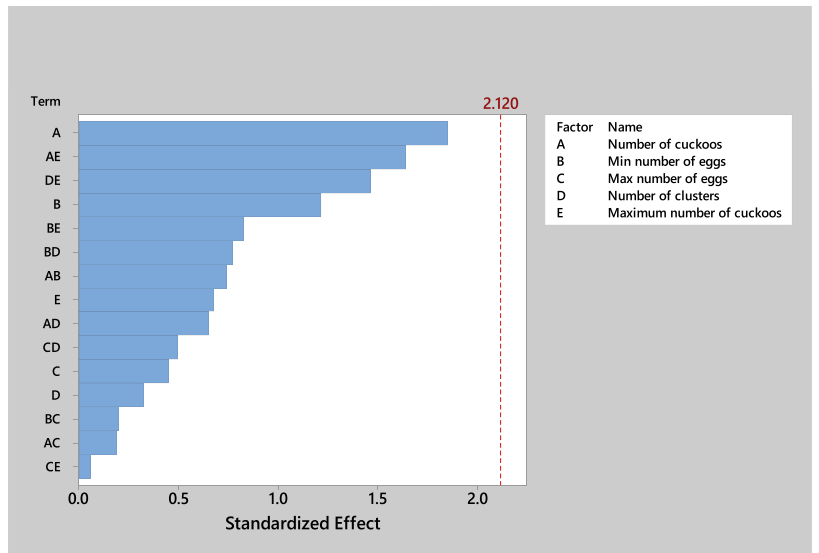

(m)

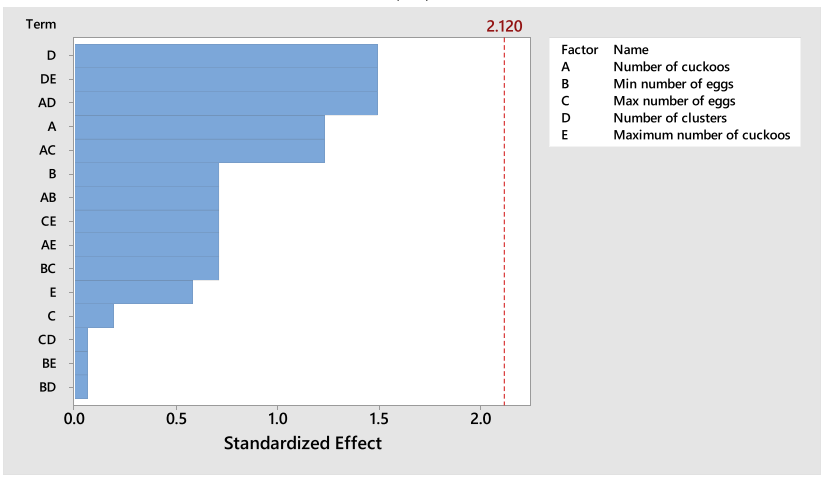

(o)

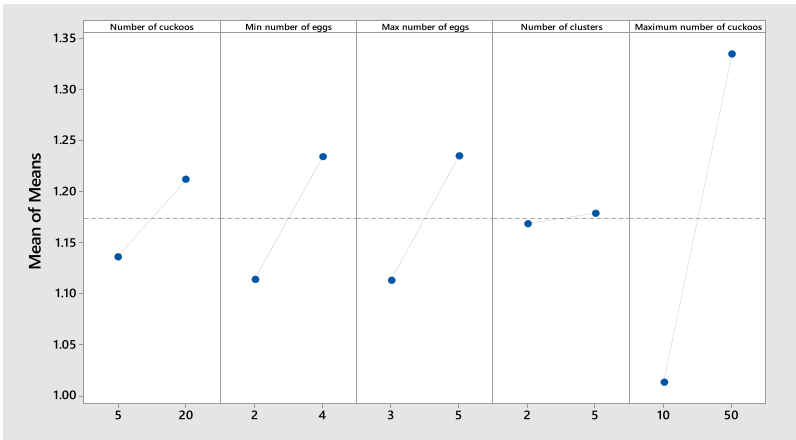

(j)

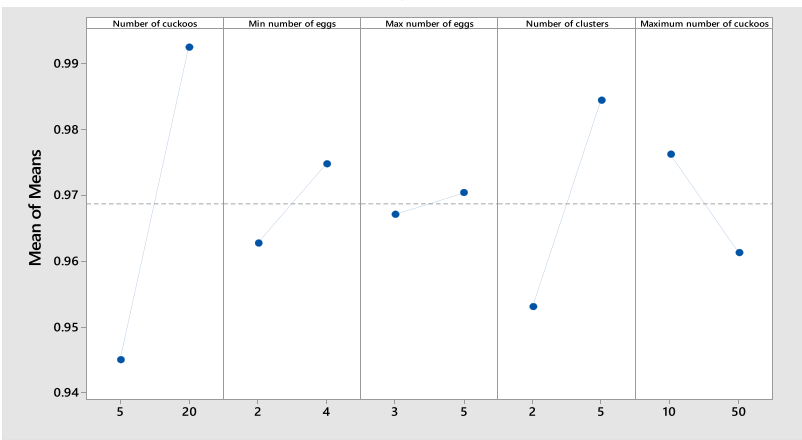

(1)

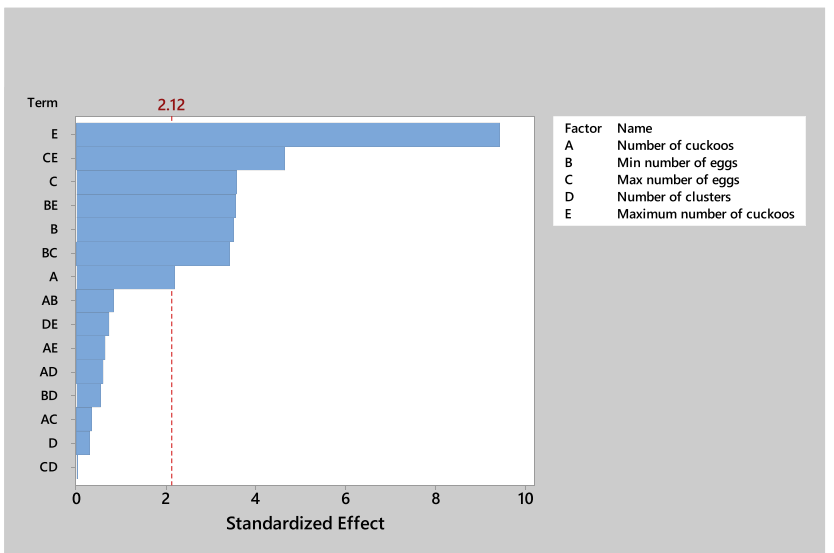

(n)

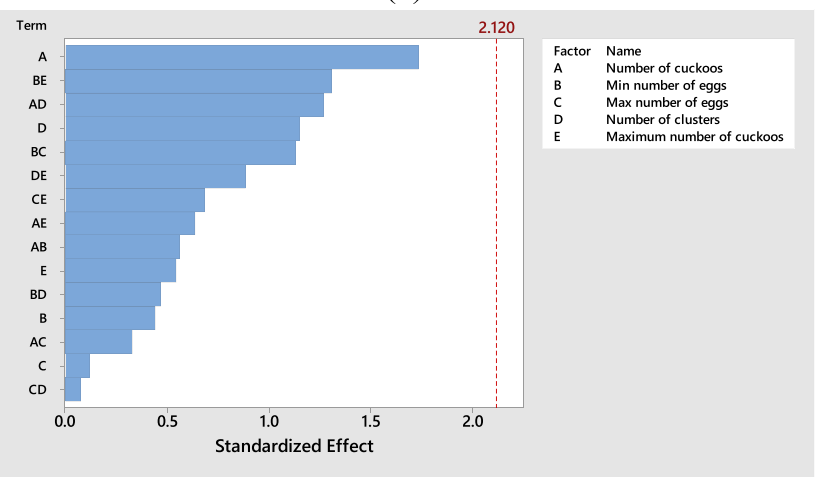

(p)

Fig. 4 (continued) 


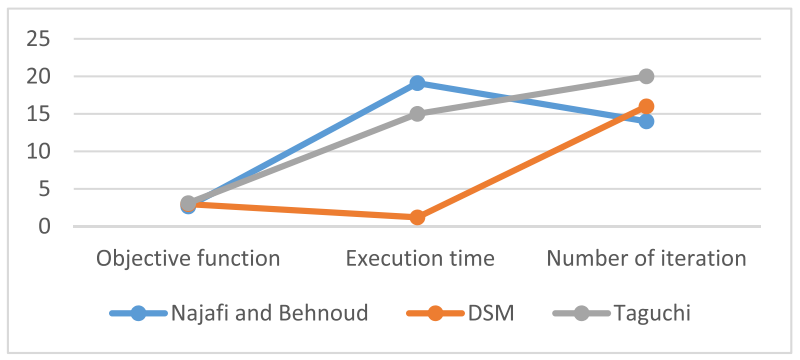

(a)

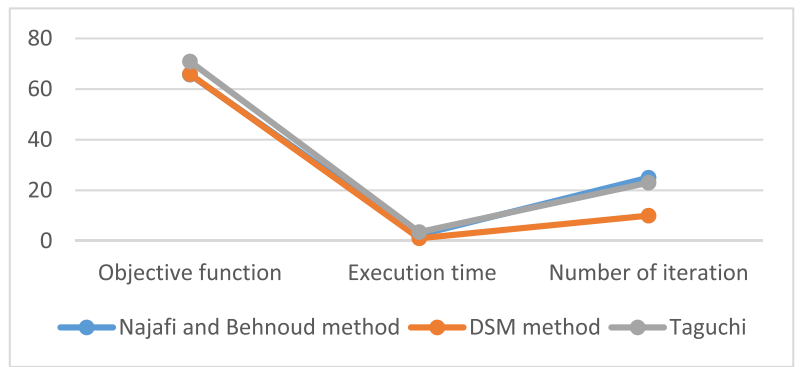

(b)

Fig. 5 Comparison of response values in DSM and Najafi and Behnoud method. a Ackley. b Rastrigin

\section{Problem description}

The proposed model is a direct and reverse single-cycle and single-purpose logistics network that includes three parts: production, consumption, and recycling. These three sections are shown in Fig. 6. The production part includes suppliers, factories, warehouses, and distribution centers. These departments are responsible for the production and production of coronavirus (vaccine) drugs. The raw materials are sent to the factory, and from the factory, coronavirus (vaccine) drugs are transported to distribution centers, while the rest are stored. Coronavirus drugs (vaccines) are delivered from distribution centers to the consumption department. Consumption includes hospitals, clinics, laboratories, and residential areas that use corona (vaccine) drugs. The recycling part includes a collection/ disinfection center, a recycling center, and a landfill. In the reverse flow, the wastes of coronavirus drugs (vaccine) are transferred from the consumption section to the collection/disinfection center. In this center, medical wastes are collected and disinfected, and from there, depending on the type of waste, it is transferred to distribution centers, factories, landfills, or recycling sites. It is assumed that corona vaccine wastes after disinfection are divided into two categories: recyclable and non-recyclable. Recyclable wastes are also divided into three categories.

A batch must be completely recycled and reused as a raw material. This group is recyclable and not dangerous and is sent to the recycling center for reuse in the factory. The second group is sent directly to the factory for further use in the production of corona medicine, and the third group is sent to the distribution center for use in the process of transporting drugs and vaccines. Non-recyclable
Fig. 6 Schematic of the proposed reverse logistics network for corona drug wastes (vaccine) Shadkam (2021a, 2021b, 2021c)

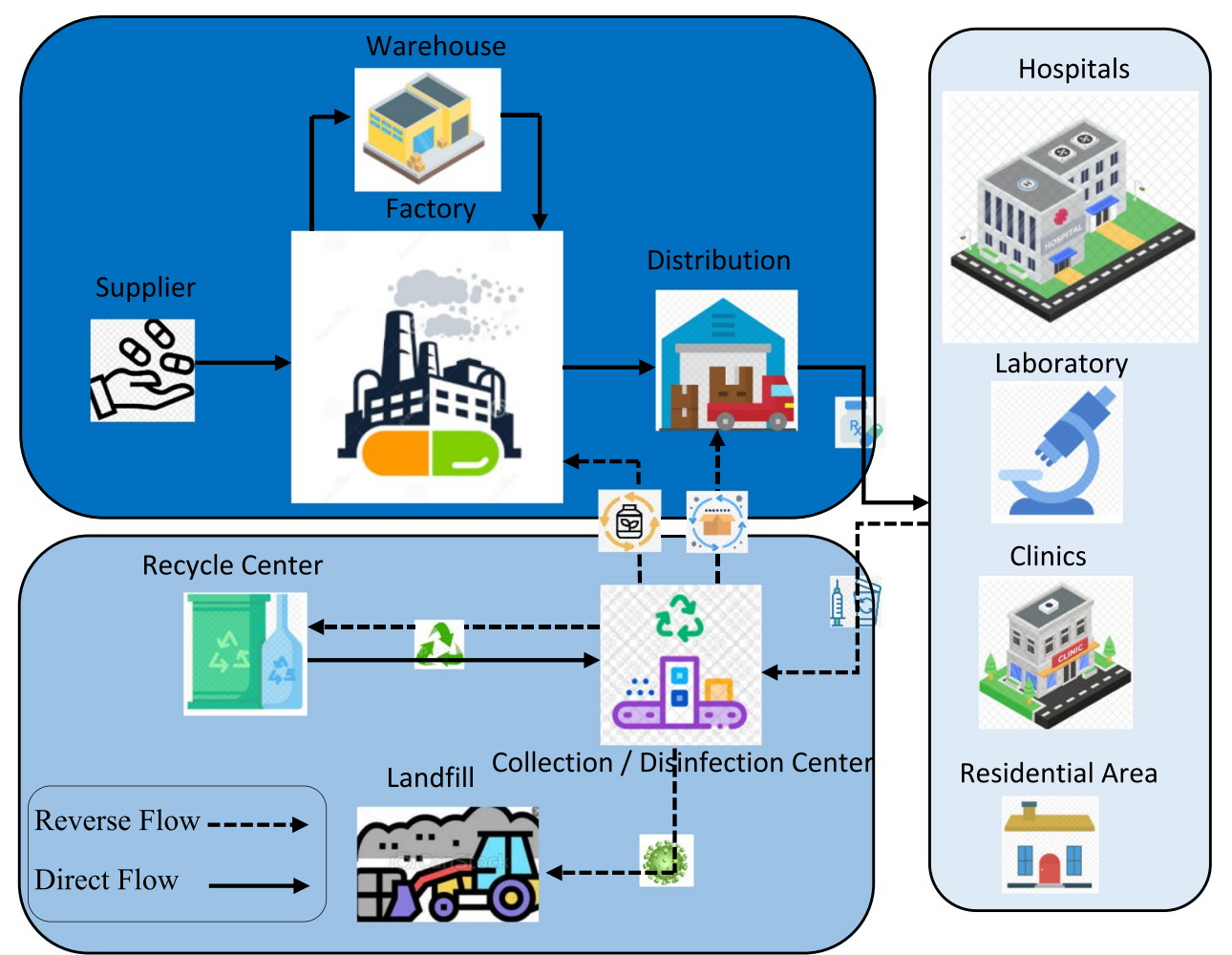


wastes are sent directly to the landfill for safe disposal and disposal. In this way, the proposed network will be a closed-loop logistics network.

\section{Index}

\begin{tabular}{lc}
\hline$I$ & Index of potential supplier centers \\
& $i \in I$ \\
\hline$J$ & Index of fixed factory centers \\
$j \in J$ & Index of potential distribution \\
& centers $k \in K$ \\
& Index of fixed consumer centers \\
& (including hospital, clinic, labo- \\
& ratory, residential area) $l \in L$ \\
& Index of potential collection/disin- \\
$M$ & fection centers $m \in M$ \\
& Index of potential recycle centers \\
$P$ & $p \in P$ \\
& Index of potential landfill centers \\
$N$ & $n \in N$ \\
\hline
\end{tabular}

\section{Parameters}

\begin{tabular}{ll}
\hline$d_{l} \quad \begin{array}{l}\text { Consumer demand (drug corona- } \\
\text { virus and vaccine) from consump- } \\
\text { tion center } l\end{array}$ \\
\hline
\end{tabular}

$r_{l}$

$B_{o}, o \epsilon\{j, p, n, k\}$

$f_{o}, o \epsilon\{k, m, p, n\}$

$c_{i j}, c_{j k}, c_{k l}, c_{l m}$

Consumer returns (wastes of drug coronavirus and vaccine) from consumption center $l$

The return rate of the wastes of drug corona from the consumption center $l$ to the collection/

Return rate from the collection/ disinfection center $m$ to: the factory center $j$, the recycle center $p$, the landfill center $n$, the distribution center $k$

The fixed cost of building a distribution center at the site $k$, collection/disinfection center at the site $m$, recycle center at the site $p$, landfill center at the site $n$

Total transportation costs of each

\begin{tabular}{|c|c|}
\hline$d_{l}$ & $\begin{array}{l}\text { Consumer demand (drug corona- } \\
\text { virus and vaccine) from consump- } \\
\text { tion center } l\end{array}$ \\
\hline$c q_{j j}$ & $\begin{array}{l}\text { Total transportation costs of each } \\
\text { unit from the factory's center } j \text { to } \\
\text { the its warehouse center }\end{array}$ \\
\hline$\overline{c q_{j k}}$ & $\begin{array}{l}\text { Total transportation costs of each } \\
\text { unit from the warehouse } j \text { to the } \\
\text { distribution center } k\end{array}$ \\
\hline$c_{m o}, o \epsilon\{p, n, j, k\}$ & $\begin{array}{l}\text { Total transportation costs of the } \\
\text { returned unit from the collec- } \\
\text { tion/disinfection center } m \text { to } \\
\text { the recycle center } p \text {, the landfill } \\
\text { center } n \text {, the factory's center } j \text {, } \\
\text { the distribution center } k\end{array}$ \\
\hline$C a_{o}, o \epsilon\{i, j, k, m, p, n\}$ & $\begin{array}{l}\text { The capacity of the supplier at site } \\
i \text {, factory at site } j \text {, distribution } \\
\text { center at the site } k \text {, collection/ } \\
\text { disinfection center at site } m, \\
\text { recycle center at site } p \text {, landfill } \\
\text { center at site } n\end{array}$ \\
\hline$C a_{j j}$ & $\begin{array}{l}\text { The warehouse capacity at the } \\
\text { place } j\end{array}$ \\
\hline$C r_{o}, o \in\{j, k\}$ & $\begin{array}{l}\text { The factory's capacity } j \text {, the } \\
\text { distribution capacity } k \text { to wastes } \\
\text { recycling }\end{array}$ \\
\hline$h_{j}$ & $\begin{array}{l}\text { The cost of maintaining each unit } \\
\text { in warehouse } j\end{array}$ \\
\hline
\end{tabular}

\section{Variables} disinfection center $m$ unit from the supplier's center $i$ to the factory's center $j$, the factory's center $j$ to distribution center $k$, the distribution center $k$ to the consumption's center $l$, consumption center $l$ to collection/disinfection center $m$

\begin{tabular}{|c|c|}
\hline$Y_{o}=\left\{\begin{array}{l}1 \\
0\end{array}, o \epsilon\{m, k, p, n\}\right.$ & $\begin{array}{l}\text { If the collection/disinfection center } m \text { is } \\
\text { constructed } 1 \text { otherwise } 0 \text {, if the distribu- } \\
\text { tion center } k \text { is constructed } 1 \text { otherwise } 0 \text {, if } \\
\text { the recycle center } p \text { is constructed } 1 \text { other- } \\
\text { wise } 0 \text {, if the landfill center } n \text { is constructed } \\
1 \text { otherwise } 0\end{array}$ \\
\hline$X_{i j}, X_{j k}, X_{k l}, X_{l m}$ & $\begin{array}{l}\text { The amount of medical products flow from } \\
\text { the supplier's center } i \text { to the factory's } \\
\text { center } j \text {, the factory's center } j \text { to the } \\
\text { distribution center } k \text {, the distribution } \\
\text { center } k \text { to the consumption center } l \text {, the } \\
\text { consumption center } l \text { to the collection/ } \\
\text { disinfection center } m\end{array}$ \\
\hline$Q_{j j}$ & $\begin{array}{l}\text { The amount of medical products flow from } \\
\text { the factory's center } j \text { to its warehouse }\end{array}$ \\
\hline$Q_{j k}$ & $\begin{array}{l}\text { The amount of medical products flow from } \\
\text { the warehouse } j \text { to the distribution center } \\
k\end{array}$ \\
\hline$X_{m o}, o \epsilon\{p, n, j, k\}$ & $\begin{array}{l}\text { The amount of return flow of medical } \\
\text { products from the collection/disinfection } \\
\text { center } m \text { to the recycle center } p \text {, landfill } \\
\text { centers } n \text {, factory's center } j \text {, distribution } \\
\text { center } k\end{array}$ \\
\hline
\end{tabular}




\begin{tabular}{l}
\hline$Y_{o}=\left\{\begin{array}{l}1 \\
0\end{array}, o \epsilon\{m, k, p, n\} \begin{array}{l}\text { If the collection/disinfection center } m \text { is } \\
\text { constructed } 1 \text { otherwise } 0, \text { if the distribu- } \\
\text { tion center } k \text { is constructed } 1 \text { otherwise } 0, \text { if } \\
\text { the recycle center } p \text { is constructed } 1 \text { other- } \\
\text { wise } 0, \text { if the landfill center } n \text { is constructed } \\
1 \text { otherwise } 0\end{array}\right.$ \\
\hline $\begin{array}{l}\text { The amount of medical products in ware- } \\
\text { house } j \text { as inventory }\end{array}$
\end{tabular}

\section{Mathematical model}

The mixed integer model for integrated reverse logistics network with the aim of reducing costs is presented as follows:

$\operatorname{MinTC}=f_{1}+f_{2}+f_{3}+f_{4}+f_{5}$

S.t.

$$
\begin{aligned}
& \sum_{k \in K} X_{k l}=d_{l} \forall l \in L \\
& \sum_{m \in M} X_{l m}=r_{l} \forall l \in L
\end{aligned}
$$

$\sum_{p \in P, n \in N, j \in J, k \in K} X_{m o}=B_{o} \sum_{l \in L} X_{l m} \forall o \epsilon\{p, n, j, k\}, \forall m \in M$

$\sum_{j \in J}\left(X_{j k}+Q_{j k}\right)=\sum_{l \in L} X_{k l}-\sum_{m \in M} X_{m k} \forall k \in K$

$\sum_{k \in K}\left(X_{j k}+Q_{j j}\right)=\sum_{l \in L} X_{i j}+\sum_{m \in M} X_{m j} \forall j \in J$

$U_{j}=Q_{j j}-\sum_{k \in K} Q_{j k} \forall j \in J$

$\sum_{k \in K} Q_{j k} \leq Q_{j j} \forall j \in J$

$\sum_{j \epsilon J} X_{i j} \leq C a_{i} \forall i \in I$

$\sum_{k \epsilon K} X_{j k}+\sum_{s \epsilon S} Q_{j j} \leq C a_{i} \forall j \in J$

$\sum_{l \epsilon L} X_{k l} \leq C a_{k} Y_{k} \forall k \in K$

$\sum_{o \epsilon\{p, n, j, k\}} \sum_{p \epsilon P, n \epsilon N, j \epsilon J, k \epsilon K} X_{m o} B_{o} \leq C a_{m} Y_{m} \forall m \epsilon M$

$\sum_{m \epsilon M} X_{m o} \leq C r_{o} Y_{o} \forall o \epsilon\{k, j\}, \forall k \epsilon K, \forall j \epsilon J$

$\sum_{m \epsilon M} X_{m o} \leq C a_{o} Y_{o} \forall o \epsilon\{n, p\}, \forall n \epsilon N, \forall p \epsilon P$

$U \leq C a_{j j} \forall j \epsilon J$ $\sum_{m \in M, k \in K, p \in P, n \in N} Y_{o} \geq 1 \forall o \epsilon\{m, k, p, n\}$

$\sum_{o \in\{j, p, n, k\}} B_{o}=1$

$Y_{0} \epsilon\{0.1\} \forall o \epsilon\{m, k, p, n\}, \forall m \epsilon M, \forall k \epsilon K, \forall p \epsilon P, n \epsilon N$

$$
X_{i j}, X_{j k}, Q_{j j}, U_{j}, X_{k l}, Q_{j k}, X_{l m}, X_{m o} \geq 0,
$$

$\forall o \epsilon\{p, n, j, k\}, \forall i \epsilon I, \forall j \epsilon J, \forall k \epsilon K, \forall l \epsilon L, \forall m \epsilon M, \forall n \epsilon N, \forall p \epsilon P$

$f_{1}=\sum_{o \in\{m, k, p, n\}} \sum_{m \in M, k \in K, p \in P, n \in N} f_{o} Y_{o}$

$f_{2}=\sum_{i \in I} \sum_{j \in J} c_{i j} X+\sum_{i j} \sum_{k \in K} c_{j k} X_{j k}+\sum_{k \in K} \sum_{l \in L} c_{k l} X_{k l}+\sum_{l \in L} \sum_{m \in M} c_{l m} X_{l m}$

$f_{3}=\sum_{j \in J} c q_{j j} Q_{j j}+\sum_{j \in J} \sum_{k \in K} c q_{j k} Q_{j k}$

$f_{4}=\sum_{o \in\{p, n, j, k\}} \sum_{m \in M} \sum_{p \in P, n \in N, j \in J, k \in K} c_{m o} X_{m o}$

$f_{5}=\sum_{j \in J} h_{j} U_{j}$

In Eq. 19 , the objective functions $\mathrm{f}_{1}$ to $\mathrm{f}_{5}$ represent fixed cost, direct transportation costs, warehouse transportation costs, reverse transportation costs, and inventory costs. These objective functions indicate the minimization of the cost of building facilities, the cost of transporting medical products directly and inversely, and inventory in accordance with Eqs. 38, 39, 40, 41, and 42. Constraints (20) and (21) ensure that all medical needs are met in direct flow and that all returned waste is collected from consumers in reverse flow. Constraints (22) to (25) are related to the flow level in the centers. Constraint (26) ensures that the output flow of the warehouse is less than the total revenue stream of the warehouse. Constraints (27) to (33) ensure that the flow is only between the centers where the facility is constructed and that the total flow in each center does not exceed its capacity. Constraint (34) ensures that at least one potential center is active. Constraints (35) ensure that the sum of the return waste coefficients is 1 . Constraints (36) and (37) determine the types of model decision variables.

\section{Solving the COVID-19 waste management model using the DSM method}

In this section, the parameters of the cuckoo optimization algorithm for use in the mentioned logistics network are 
Table 6 Optimal values of the cuckoo meta-heuristic algorithm parameters and optimal criteria for the proposed logistics problem from experimental method

\begin{tabular}{lll}
\hline & Experimental method & DSM method \\
\hline Parameter & & \\
Number of clusters & 4 & 3 \\
Initial number of cuckoos & 4 & 6 \\
Max number of cuckoos & 20 & 17 \\
Min number of eggs & 3 & 4 \\
Max number of eggs & 5 & 6 \\
Criteria & & \\
Objective function & $1,942,717.3191$ & $1,911,509.8228$ \\
Number of iteration & 201 & 201 \\
Execution time (s) & 5483 & 4765 \\
\hline
\end{tabular}

examined. These parameters are examined and compared using two approaches, including the experimental approach and the DSM method. The optimal parameters of the cuckoo algorithm using the experimental approach are shown in Table 6. Also, after implementing the DSM method in a similar way in the previous sections, the results are as shown in Table 6. In order to compare the performance of both methods, the criteria of the value of the objective function, execution time, and number of iterations are calculated using the configuration of both methods (Table 6). Also, the convergence diagram of the value of the objective function and the number of iterations for both approaches is shown in Fig. 7. As can be seen, using the parameters created from the proposed method of the paper, a better objective function can be achieved in the same iterations with less execution time than the experimental approach, which shows the optimal performance of the proposed method.

Also, in order to compare the efficiency of both methods, the values of Table 6 are considered as inputs, and the values of Table 6 are considered as outputs, and after implementing the CCR model of data envelopment analysis, the efficiency values are calculated. To better differentiate between the two methods, the CCR model is allowed to obtain performance values greater than one. The results show an efficiency value of 1.23456 for the proposed method and efficiency value of 0.98753 for the experimental method. Therefore, it can be seen that the efficiency of the proposed method is better than the experimental method.

\section{Conclusion}

In this paper, the hybrid DSM method was presented by combining two methods of RSM and DEA. One of the advantages of the DSM method is the reduction in the number of response surfaces to one efficiency surface, and

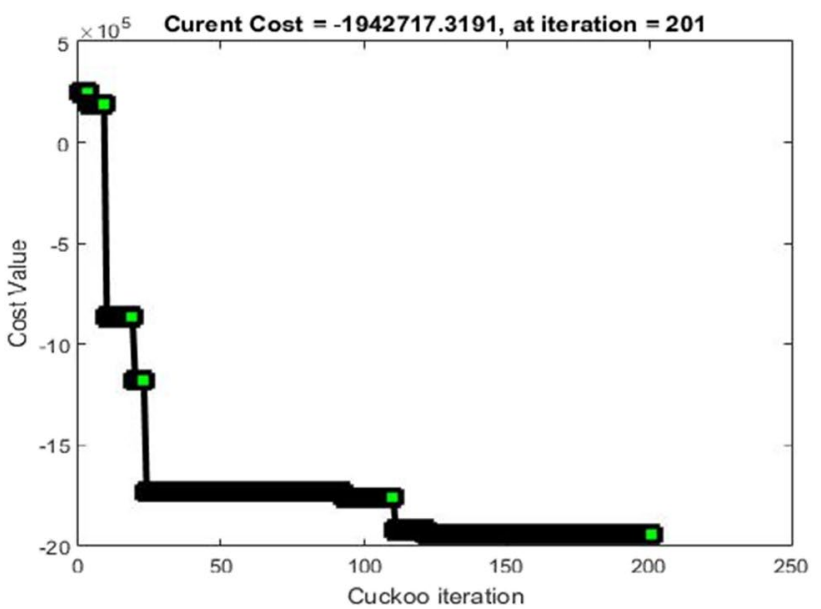

(a)

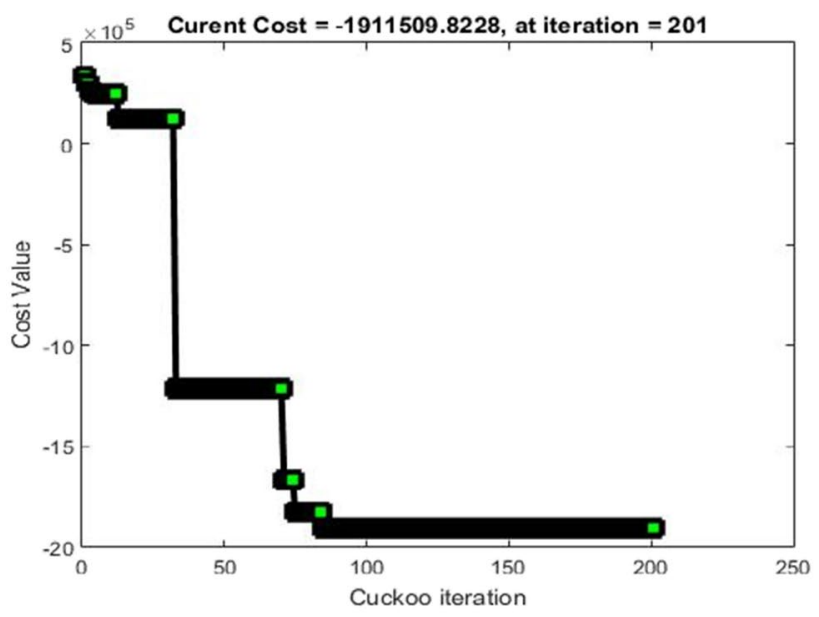

(b)

Fig. 7 The implementation of the cuckoo algorithm on the proposed inverse logistics network based on the a experimental method and $\mathbf{b}$ DSM method

instead of optimizing multiple response surfaces for the problem outputs, only efficiency surface optimization is considered. With this proposed method, in addition to optimizing the objective function of the problem, it is possible to maximize its efficiency simultaneously. In this paper, the hybrid DSM method was used to set the optimal parameters of the COA. In order to evaluate the performance of the DSM method, two types of problems were investigated, which included standard functions and COVID-19 waste management problem. Standard functions include Ackley and Rastrigin functions. In order to validate the proposed method, the Taguchi and the Najafi and Behnoud methods were implemented and the results of the proposed method were compared with these methods. The numerical results indicate the higher efficiency of the proposed DSM hybrid algorithm. Then, the cuckoo algorithm parameter was adjusted using the proposed method for the inverse logistics 
problem of COVID-19 waste, and the results were compared with the experimental approach which shows the superiority of the proposed method over the experimental method according to the objective function, execution time and efficiency value.

Finally, it can be said that by setting the parameters of meta-heuristic algorithms scientifically, errors related to trial and error can be avoided. As future research, the DSM method can be used to parameterize other meta-heuristic algorithms, and by assigning appropriate values to the effective parameters in the algorithms, a suitable and acceptable solution can be achieved in the shortest time and with the least error and high reliability. Also, the process in this paper can also be applied similarly to other real-world problems.

Author contribution The whole process of the preparing the paper, including coding, modeling, and writing, etc., has been done by Elham Shadkam.

Code availability All paper codes are written by the author with the Lingo and Mititab software and can be presented if needed.

\section{Declarations}

Consent for publication The author agrees to participate and publish.

Competing interests The author declares no competing interests.

\section{References}

Adu, R. O., Gyasi, S. F., Essumang, D. K., \& Otabil, K. B. (2020). Medical waste-sorting and management practices in five hospitals in Ghana. J Environ Public Health 2020

Akbarzadeh, A., \& Shadkam, E. (2015). The study of cuckoo optimization algorithm for production planning problem. arXiv 1508:01310

Al-Refaie, A., \& Al-Hawadi, A. (2021). Optimal fuzzy repairs' scheduling and sequencing of failure types over multiple periods. J Amb Intell Human Comput 1-17

Alavi A, Dolatabadi M, Mashhadi J, Farsangi EN (2021) Simultaneous optimization approach for combined control-structural design versus the conventional sequential optimization method. Struct Multidiscip Optim 63(3):1367-1383

Almeida J (2010) A cost optimization model for hazardous medical waste management in Portugal. Instituto Superior Técnico, Universidade Técnica de Lisboa, Lisbon

Alshraideh H, Qdais HA (2017) Stochastic modeling and optimization of medical waste collection in Northern Jordan. J Mater Cycles Waste Manage 19(2):743-753

Azadeh A, Sheikhalishahi M, Firoozi M, Khalili S (2013) An integrated multi-criteria Taguchi computer simulation-DEA approach for optimum maintenance policy and planning by incorporating learning effects. Int J Prod Res 51(18):5374-5385

Bartz-Beielstein, T., \& Markon, S. (2004). Tuning search algorithms for real-world applications: a regression tree based approach.
Proceedings of the 2004 Congress on Evolutionary Computation (IEEE Cat. No. 04TH8753)

Beielstein, T., Parsopoulos, K. E., \& Vrahatis, M. N. (2002). Tuning PSO parameters through sensitivity analysis. Universitätsbibliothek Dortmund.

Borhanifar, Z., \& Shadkam, E. (2016). The new hybrid COAW method for solving multi-objective problems. arXiv:1611.00577.

Budak A, Ustundag A (2017) Reverse logistics optimisation for waste collection and disposal in health institutions: the case of Turkey. Int J Log Res Appl 20(4):322-341

Cheng B-W, Chang C-L (2007) A study on flowshop scheduling problem combining Taguchi experimental design and genetic algorithm. Expert Syst Appl 32(2):415-421

Cheng, M.-Y., Fang, Y.-C., \& Wang, C.-Y. (2021). Auto-tuning SOS algorithm for two-dimensional orthogonal cutting optimization. KSCE J Civil Eng 1-15.

Črepinšek M, Ravber M, Mernik M, Kosar T (2019) Tuning multiobjective evolutionary algorithms on different sized problem sets. Mathematics 7(9):824

Devarapalli, R., \& Bhattacharyya, B. (2021). Optimal controller parameter tuning of PSS using sine-cosine algorithm. In Metaheuristic and Evolutionary Computation: Algorithms and Applications (pp. 337-360). Springer.

Do Ngoc Luu, N. N. P., \& Anh, D. T. (2021). Tuning parameters in deep belief networks for time series prediction through harmony search. Int J Mach Lear Comput 11(4)

Fallahi M, Amiri S, Yaghini M (2014) A parameter tuning methodology for metaheuristics based on design of experiments. Int J Eng Technol Sci Sciences 2(6):497-521

Fletcher, C., Clair, R. S., \& Sharmina, M. (2021). A framework for assessing the circularity and technological maturity of plastic waste management strategies in hospitals. J Cleaner Prod 127169

Gergin Z, Tunçbilek N, Esnaf Ş (2019) Clustering approach using artificial bee colony algorithm for healthcare waste disposal facility location problem. Int J Oper Res Inf Syst (IJORIS) 10(1):56-75

Gomes GF, de Almeida FA (2020) Tuning metaheuristic algorithms using mixture design: application of sunflower optimization for structural damage identification. Adv Eng Soft 149:102877

Gorjestani, M., Shadkam, E., Parvizi, M., \& Aminzadegan, S. (2015). A hybrid COA-DEA method for solving multi-objective problems. arXiv: 1509.00595

Hasani A, Mokhtari H, Fattahi M (2021) A multi-objective optimization approach for green and resilient supply chain network design: a real-life case study. J Clean Prod 278:123199

Hinkelmann, K., \& Kempthorne, O. (1994). Design and analysis of experiments (Vol. 1). Wiley Online Library

Homayouni Z, Pishvaee MS (2020) A bi-objective robust optimization model for hazardous hospital waste collection and disposal network design problem. J Mater Cycles Waste Manage 22(6):1965-1984

Hosnavi R, Nekooie MA, Khalili SM, Tavakoli A (2019) A resilient supply portfolio considering political and disruption risks. Int J Ind Syst Eng 31(2):209-249

Joshi SK, Bansal JC (2020) Parameter tuning for meta-heuristics. Knowledge-Based Systems 189:105094

Julianelli V, Caiado RGG, Scavarda LF, Cruz SP, d. M. F. (2020) Interplay between reverse logistics and circular economy: critical success factors-based taxonomy and framework. Res Conserv Recyc 158:104784

Kahramanli H (2012) A modified cuckoo optimization algorithm for engineering optimization. Int J Future Comput Commun 1(2):199 
Kargar S, Paydar MM, Safaei AS (2020a) A reverse supply chain for medical waste: a case study in Babol healthcare sector. Waste Manage 113:197-209

Kargar S, Pourmehdi M, Paydar MM (2020) Reverse logistics network design for medical waste management in the epidemic outbreak of the novel coronavirus (COVID-19). Sci Total Environ $746: 141183$

Kazikova, A., Pluhacek, M., \& Senkerik, R. (2020). Why tuning the control parameters of metaheuristic algorithms is so important for fair comparison? Mendel,

Khalili, S. M., Babagolzadeh, M., Yazdani, M., Saberi, M., \& Chang, E. (2016). A bi-objective model for relief supply location in postdisaster management. 2016 International Conference on Intelligent Networking and Collaborative Systems (INCoS),

Khalili SM, Jolai F, Torabi SA (2017) Integrated production-distribution planning in two-echelon systems: a resilience view. Int J Prod Res 55(4):1040-1064

Latorre-Biel JI, Ferone D, Juan AA, Faulin J (2021) Combining simheuristics with Petri nets for solving the stochastic vehicle routing problem with correlated demands. Exp Syst Appl 168:114240

Lobo, F., Lima, C. F., \& Michalewicz, Z. (2007). Parameter setting in evolutionary algorithms (Vol. 54). Springer Science \& Business Media.

Mergos, P. E., \& Yang, X.-S. (2021). Flower pollination algorithm parameters tuning. Soft computing, 1-19.

Naderi B, Zandieh M, Roshanaei V (2009) Scheduling hybrid flowshops with sequence dependent setup times to minimize makespan and maximum tardiness. Int $\mathbf{J}$ Adv Manuf Technol 41(11-12):1186-1198

Najafi, S. E., \& Behnoud, R. (2015). Consolidated technique of response surface methodology and data envelopment analysis for setting the parameters of meta-heuristic algorithms-case study: production scheduling problem.

Nolz PC, Absi N, Feillet D (2014) A stochastic inventory routing problem for infectious medical waste collection. Networks 63(1):82-95

Odili, J. B., \& Fatokun, J. O. (2020). The mathematical model, implementation and the parameter-tuning of the African buffalo optimization algorithm. 2020 International Conference in Mathematics, Computer Engineering and Computer Science (ICMCECS),

Osaba E, Yang X-S, Fister I Jr, Del Ser J, Lopez-Garcia P, VazquezPardavila AJ (2019) A discrete and improved bat algorithm for solving a medical goods distribution problem with pharmacological waste collection. Swarm Evol Comput 44:273-286

Özakın AN, Kaya F (2020) Experimental thermodynamic analysis of air-based PVT system using fins in different materials: optimization of control parameters by Taguchi method and ANOVA. Sol Energy 197:199-211

Ozkaya, I., Gor, A., Sogut, M., Gundogdu, N., Hosoglu, F., \& Kiris, A. (2020). Significant density change in medical waste during Covid19 pandemic and effects on medical waste management in Istanbul. 5th Eurasia Waste Management Symposium,

Phan HD, Ellis K, Barca JC, Dorin A (2020) A survey of dynamic parameter setting methods for nature-inspired swarm intelligence algorithms. Neural Comput Appl 32(2):567-588

Rajabioun R (2011) Cuckoo Optimization Algorithm. Appl Soft Comput 11(8):5508-5518

Rastrigin LA (1974) Systems of extremal control. Nauka

Ridge, E. (2007). Design of experiments for the tuning of optimisation algorithms. Citeseer.

Ridge, E., \& Kudenko, D. (2007). Analyzing heuristic performance with response surface models: prediction, optimization and robustness. Proceedings of the 9th annual conference on Genetic and evolutionary computation,
Rudolph, G. (1990). Globale Optimierung mit parallelen Evolutionsstrategien Diplomarbeit, Universit at Dortmund, Fachbereich Informatik].

Saeheaw T (2020) Parameter tuning of the HCSCROCFO-3Opt algorithm for solving the capacitated vehicle routing problem. Int $\mathbf{J}$ Ind Eng Comput 11(4):481-490

Sangkham, S. (2020). Face mask and medical waste disposal during the novel COVID-19 pandemic in Asia. Case Studies in Chemical and Environmental Engineering, 2, 100052.

Saremi A, ElMekkawy T, Wang G (2007) Tuning the parameters of a memetic algorithm to solve vehicle routing problem with backhauls using design of experiments. Int J Oper Res 4(4):206-219

Shadkam, E. (2021). Cuckoo optimization algorithm in reverse logistics: a network design for COVID-19 waste management. Waste Management \& Research 0734242X211003947

Shadkam, E., \& Bijari, M. (2014). Evaluation the efficiency of cuckoo optimization algorithm. arXiv preprint arXiv:1405.2168.

Shadkam E, Bijari M (2015) The optimization of bank branches efficiency by means of response surface method and data envelopment analysis: a case of Iran. Asian Finan Econ Bus 2(2):13-18

Shadkam E, Bijari M (2017) Multi-objective simulation optimization for selection and determination of order quantity in supplier selection problem under uncertainty and quality criteria. Int T Adv Manuf Technol 93(1):161-173

Shadkam E, Bijari M (2020) A novel improved cuckoo optimisation algorithm for engineering optimisation. Int J Artif Intell Soft Comput 7(2):164-177

Shadkam, E., Delavari, R., Memariani, F., \& Poursaleh, M. (2015). Portfolio selection by the means of cuckoo optimization algorithm. arXiv preprint arXiv:1508.01314.

Shadkam, E., \& Jahani, N. (2015). A hybrid COA $\varepsilon$-constraint method for solving multi-objective problems. ArXiv:1509.08302

Shadkam E, Khajooei S, Rajabi R (2021) The new TOPCO hybrid algorithm to solve multi-objective optimisation problems: the integrated stochastic problem of production-distribution planning in the supply chain. Int J Comput Syst Eng 6(3):143-157

Shadkam E (2021b) The problem of resource leveling in multi-project mode by cuckoo optimization algorithm. Int J Math Oper Res 20:1-20

Shadkam E (2021c) A novel two-phase algorithm for a centralized production planning problem by symmetric weighted DEA approach: a case study in energy efficiency. Eur Jo Ind Eng 15:1-20

Shi, L., Fan, H., Gao, P., \& Zhang, H. (2009). Network model and optimization of medical waste reverse logistics by improved genetic algorithm. International Symposium on Intelligence Computation and Applications

Shih L-H, Lin Y-T (2003) Multicriteria optimization for infectious medical waste collection system planning. Pract Period Hazard Toxic Radioact Waste Manag 7(2):78-85

Šilc, J., Taškova, K., \& Korošec, P. (2015). Data mining-assisted parameter tuning of a search algorithm. Informatica 39(2)

Thirumalai R, Seenivasan M, Panneerselvam K (2021) Experimental investigation and multi response optimization of turning process parameters for Inconel 718 using TOPSIS approach. Mater Today Proc 45:467-472

Tien Bui D, Abdullahi MAM (2021) Fine-tuning of neural computing using whale optimization algorithm for predicting compressive strength of concrete. Eng Comput 37(1):701-712

Veček N, Mernik M, Filipič B, Črepinšek M (2016) Parameter tuning with chess rating system (CRS-Tuning) for meta-heuristic algorithms. Inf Sci 372:446-469

Vickers NJ (2017) Animal communication: when I'm calling you, will you answer too? Curr Biol 27(14):R713-R715 
Walker DJ, Craven MJ (2020) Identifying good algorithm parameters in evolutionary multi-and many-objective optimisation: a visualisation approach. Appl Soft Comput 88:105902

Wang J, Shen J, Ye D, Yan X, Zhang Y, Yang W, Li X, Wang J, Zhang L, Pan L (2020) Disinfection technology of hospital wastes and wastewater: suggestions for disinfection strategy during coronavirus Disease 2019 (COVID-19) pandemic in China. Environ Pollut 262:114665

Wang T-Y, Wu K-B (1999) A parameter set design procedure for the simulated annealing algorithm under the computational time constraint. Comput Oper Res 26(7):665-678

Xu J, Chiu SY, Glover F (1998) Fine-tuning a tabu search algorithm with statistical tests. Int Trans Oper Res 5(3):233-244
Yazdani M, Aleti A, Khalili SM, Jolai F (2017a) Optimizing the sum of maximum earliness and tardiness of the job shop scheduling problem. Comput Ind Eng 107:12-24

Yazdani M, Khalili SM, Babagolzadeh M, Jolai F (2017b) A singlemachine scheduling problem with multiple unavailability constraints: a mathematical model and an enhanced variable neighborhood search approach. J Comput Design Eng 4(1):46-59

Yazdani, M., Khalili, S. M., \& Jolai, F. (2016). A parallel machine scheduling problem with two-agent and tool change activities: an efficient hybrid metaheuristic algorithm. Int J Comput Integr Manuf 1-14

Publisher's note Springer Nature remains neutral with regard to jurisdictional claims in published maps and institutional affiliations. 